\title{
GESTIÓN DEL CARBONO: ¿UNA ALTERNATIVA EFECTIVA CONTRA EL CALENTAMIENTO GLOBAL?
}

\author{
CARBON MANAGEMENT: AN ALTERNATIVE EFFECTIVE AGAINST \\ GLOBAL WARMING?
}

\section{CATYA VÁSQUEZ TARAZONA}

Docente Auxiliar de la Facultad de Ciencias Contables, UNMSM

Recepción: Febrero de 2011/ Conformidad: Abril de 2011

\section{RESUMEN}

El cambio climático de nuestro planeta y otros factores que lo contaminan, podrían provocar una catástrofe de grandes dimensiones, haciendo peligrar la propia existencia humana. Desde una perspectiva mundial, el dióxido de carbono es el gas de efecto invernadero más importante de los que hoy en día, altera la climatología de la Tierra.

De este modo, la problemática del balance global del carbono es que todos participamos en el ciclo del carbono, ya sea conduciendo, utilizando electricidad producida mediante combustibles fósiles (petróleo, gas), ingiriendo alimentos o mediante la descomposición de la inmensa cantidad de materia orgánica contenida en los bosques que fueron destruidos (tala, quema), etc.

En ese sentido, la prioridad de los países debe orientarse en aunar esfuerzos para la gestión del carbono, esto es, gestionar el balance global de carbono, con la finalidad de que la concentración de dióxido de carbono en la atmósfera se mantenga en niveles de seguridad y de esa manera evitar nuestra propia autodestrucción así como efectos devastadores sobre los ecosistemas.

La idea es que todos los agentes económicos tomemos conciencia sobre el balance final de las emisiones de dióxido de carbono y su influencia en el calentamiento global,

\begin{abstract}
Climate change on our planet and Factors That other contaminants, a major cause It Could catastrophe, endangering human existence. From a global perspective, carbon dioxide greenhouse gas is the MOST important today, alters the climate of the Earth. THUS, the problem of global coal Is That balance we all cycle Participate in the coal, whether driving, using electricity produced by fossil fuels (oil, gas), by eating or by the decomposition of the Vast amount of organic matter in the forests Contained Were Destroyed (cutting, burning, etc.)..

In That sense, the priority Countries Should Work Together to AIM to Carbon management, ie managing the Global Carbon balance, in order That the concentration of carbon dioxide in the atmosphere is Maintained Levels and safe at our own THUS Avoid self-destruction and Devastating effects on ecosystems.

The Idea Is That all actors Economic Become aware of the final balance of carbon dioxide Emissions and Their Impact on global warming, an Environmentally Responsible Behavior Requiring change to Ensure the preservation of the conservation and environment.
\end{abstract}

* Magister en Contabilidad con Mención Política y Administración Tributaria - UNMSM. Con Especialización en Auditoría Tributaria

E- mail: catyavasquez@gmail.com 
requiriéndose un cambio de conductas ambientalmente responsables que garanticen la conservación y preservación del medio ambiente.

Palabras clave: Balance global , Economía del ambiente, Estrategias de Desarrollo, Gestión de Recursos

\section{INTRODUCCIÓN}

Las actividades económicas en general se inician con la extracción de los recursos naturales y concluyen con la emisión o el depósito de residuos en el medio ambiente. Razón por la cual, es necesario diferenciar el ámbito de la economía ambiental conocida también como economía del medio ambiente y la economía de los recursos naturales.

Los autores Labandeira, León y Vásquez${ }^{1}$ consideran que dentro del ámbito de la economía ambiental se encuentran los temas relacionados con la función del medio ambiente como receptor y asimilador de residuos, esto es, como sustentador de ciertos procesos bióticos y abióticos de recuperación y regeneración de subproductos derivados de los procesos de producción y consumo. La economía ambiental define el problema de la degradación ambiental como una falla de mercado generado por la existencia de una externalidad negativa o por la caracterización del bien ambiental como público ${ }^{2}$.
Key words: Overall balance, environmental economics, Development Strategies, Resources Management

En cambio, la economía de los recursos naturales abarca la gestión de los recursos naturales, renovables y no renovables, intentando resolver conflictos entre usos alternativos y con el objetivo de alcanzar la pauta óptima de agotamiento, cuando se refiere a los recursos no renovables o la sostenibilidad en su uso cuando se trata de los recursos renovables.

Sin embargo, ambas áreas de la economía están orientadas a impulsar estrategias de desarrollo fundamentadas en el uso eficiente y sostenible de los recursos naturales, renovables y no renovables, tomando en cuenta los impactos, positivos y negativos, que puedan ocasionarse en el ambiente, de tal forma que se contribuya con el desarrollo sostenible así como con la mejora de la calidad de vida de la población.

\section{RECURSOS NATURALES}

Según José Paschoal ${ }^{3}$, de la variedad de recursos que los sistemas económicos movi-

1 LABANDEIRA Xavier - LEÓN Carmelo J. - VÁSQUEZ Xosé, Economía Ambiental, Editorial Pearson Educación S.A., 356 páginas, España 2007, páginas 12-14.

2 Las externalidades son actividades que afectan a terceros, positiva o negativamente, sin que éstos (beneficiados o afectados) paguen o sean pagados por dichas actividades respectivamente. La presencia de externalidades tanto positivas como negativas hace que el mercado falle en asignar eficientemente los recursos.

Un ejemplo de externalidad negativa es la contaminación, en la cual una empresa pesquera arroja desechos contaminantes al mar, con lo cual perjudica a los pescadores de la zona y la salud de la población. Si no se paga estos efectos, habrá un nivel ineficiente alto de contaminación, por lo que disminuirá el bienestar de las familias. Los derechos claramente establecidos ayudan a prevenir las externalidades negativas, porque permiten a los afectados solicitar una compensación por los daños ocasionados. Un ejemplo de externalidad positiva es la que se deriva de los programas sanitarios públicos, como la vacuna contra el cólera o la tifoidea; las vacunas no sólo protegen a las personas que han sido vacunadas sino también a otras personas a las que éstas podrían contagiar.

3 PASCHOAL ROSSETTI José, Introducción a la Economía; Décimo octava edición, Ediciones OXFORD, 866 páginas, México 2000. 
lizan en el desarrollo del proceso de producción, las reservas naturales o el factor tierra constituyen la base sobre la cual se ejercen las presiones y las actividades de los demás recursos. En ese sentido, el alcance y tipología del factor tierra comprende lo siguiente: 1) el suelo, 2) el subsuelo, 3) el agua, 4) la pluviosidad y clima, 5) la flora y fauna, 6) otros factores.

Son los factores que intervienen o son utilizados para la producción de bienes y servicios, los cuales son aportados por la naturaleza, como el suelo, subsuelo, flora, fauna, etc ${ }^{4}$. La diversidad de los recursos naturales que poseen los distintos países son responsables de algunas de las diferencias entre sus niveles de vida. Los recursos naturales, en relación a su capacidad de autorrenovación, pueden ser: recursos no renovables y recursos renovables 5 .

Recursos no renovables. Recursos naturales que sólo se pueden usar una vez y que no se pueden reemplazar una vez que han sido utilizados. Son aquellos recursos que no pueden aumentarse mediante la producción y se encuentran presentes en la naturaleza en cantidades fijas, de tal manera que el consumo de los mismos en el período implica que habrá menos disponible para períodos futuros.

A su vez, los recursos naturales no renovables pueden ser: recursos no recuperables y recuperables. Son recursos no recuperables cuando su utilización o consumo del recurso implica su completa destrucción, abarcando su regeneración períodos muy amplios desde la perspectiva humana. Se consideran recursos naturales no renovables a los combustibles fósiles (petróleo, carbón y gas natural). En cambio un recurso es recuperable cuando el uso del recurso implica su destrucción completa en la forma actual, pero es recuperable en un futuro más o menos inmediato por medio de un proceso industrial de reciclado. Ejemplos de este tipo de recursos son determinados minerales como el hierro, el cobre, la plata, etc ${ }^{6}$.

Recursos renovables. Recursos naturales que se pueden usar repetidas veces sin agotar lo que queda disponible para el uso de las generaciones futuras. Se caracterizan porque su uso produce también el agotamiento o destrucción de la unidad consumida, pero a continuación se produce la regeneración automática del mismo según un mecanismo de reproducción de base biológica. Son ejemplos de este tipo de recursos las pesquerías, los bosques, las praderas, etc.

Sin embargo, una explotación que supere la capacidad de regeneración o renovación biológica del recurso (sobre explotación) lo convierte inmediatamente en no renovable $y$, en casos extremos, en no recuperable. También existe una forma indirecta de extinción de los recursos renovables y es la alteración del ecosistema o hábitat en el que las especies viven y se desarrollan.

Recursos ambientales. Algunos autores sostienen que los recursos ambientales están dentro de los recursos naturales renovables y para otros, es una categoría distinta de re-

4 El artículo 3 de la Ley 26811, Ley Orgánica para el Aprovechamiento sostenible de los recursos naturales, establece que son recursos naturales todo componente de la naturaleza, susceptible de ser aprovechado por el ser humano y que tenga valor actual o potencial en el mercado. Sin embargo, se debe precisar que no es exacto que se vincule a los recursos naturales con el valor en el mercado, ya que el mercado no es lo único que rige cuando nos referimos a satisfacción de necesidades. Existen muchas cosas que se encuentran en la naturaleza bastante útiles que no tienen valor en el mercado. Por ejemplo, las plantas medicinales desconocidas por la mayoría de personas que no tienen valor y por tanto no están en el mercado.

5 La clasificación de los recursos naturales en renovables y no renovables, resulta útil únicamente con fines descriptivos, ya que la mayoría de autores se oponen a esta clasificación, debido a que en gran medida la capacidad de renovación o no de un recurso natural depende de la actitud humana al servirse de él.

6 LABANDEIRA Xavier - LEÓN Carmelo J. - VÁSQUEZ Xosé, Economía Ambiental, Obra citada, página 13. 
curso natural. Labandeira, León y Vásquez ${ }^{7}$ sostienen que para los recursos ambientales su uso no implica su agotamiento o en caso de agotarse, su velocidad de reproducción o regeneración es muy rápida. Para estos recursos el mecanismo de reproducción es de tipo físico (no biológico). Son considerados recursos ambientales el agua, el aire, el paisaje, etc., pero también el medio como depósito y asimilador natural de residuos. Análogamente a lo que ocurriría con los recursos naturales renovables, un uso excesivo o irracional de los recursos ambientales, superando su tasa de regeneración natural (o capacidad de asimilación), puede amenazar la supervivencia del propio recurso, incluso hasta convertirlo en no recuperable, o de muy difícil recuperación. Ejemplos de este tipo de amenazas irreversibles son las pérdidas de la capa superficial del suelo por erosión, el agujero de la capa de ozono, la contaminación de algunos mares interiores, la sobreexplotación o contaminación de acuíferos, etc.

El Artículo 66 de la Constitución establece que "Los recursos naturales, renovables y no renovables, son patrimonio de la $\mathrm{Na}$ ción. El Estado es soberano en su aprovechamiento.

Por ley orgánica se fijan las condiciones de su utilización y de su otorgamiento a particulares. La concesión otorga a su titular un derecho real, sujeto a dicha norma legal".

De acuerdo con nuestra Constitución, los recursos naturales son patrimonio de la nación por su importancia para el conjunto del país. No pueden ser propiedad privada de personas particulares. Sin embargo, su utilización puede ser realizada tanto por el Estado como por particulares, según lo establezcan las leyes de nuestro país.

Asimismo, señala que cuando se entreguen a particulares, se les dará en concesión y ésta les otorgará un derecho real, esto es, un derecho directo sobre los recursos naturales, aunque no será el derecho de propiedad.

En el ámbito gubernamental, la concesión es el derecho que otorga una autoridad gubernamental a una persona natural o jurídica para desempeñar algunas funciones económicas. Por ejemplo, una empresa de servicio público de energía eléctrica podría tener el derecho, de acuerdo con los términos de la concesión, de usar propiedad urbana para proporcionar servicio de energía eléctrica a los residentes de la localidad.

\section{Medio ambiente}

Denominado también naturaleza o simplemente ambiente. De acuerdo con Carlos Andaluz $^{8}$ el ambiente es el conjunto de elementos sociales, económicos, culturales, bióticos y abióticos que interactúan en un espacio y tiempo determinado; lo cual podría graficarse como la sumatoria de la naturaleza $y$ las manifestaciones humanas en un lugar y tiempo concretos ${ }^{9}$.

En el medio ambiente encontramos:

1) Seres no vivos, abióticos, inanimados o inertes. Se caracterizan porque no tienen vida y pertenecen al mundo inorgánico (sin vida).

7 LABANDEIRA Xavier - LEÓN Carmelo J. - VÁSQUEZ Xosé, Economía Ambiental, Obra citada, página 13.

8 ANDALUZ WESTREICHER Carlos, Manual de Derecho Ambiental, Editorial Iustitia, 958 páginas, Lima 2009, página 62.

9 El artículo 2.3 de la Ley General del Ambiente, establece que el ambiente comprende a los elementos físicos, químicos y biológicos de origen natural o antropogénico que, en forma individual o asociada, conforman el medio en que se desarrolla la vida, siendo los factores que aseguran la salud individual o colectiva de las personas y la conservación de los recursos naturales, la diversidad biológica y el patrimonio cultural asociado a ellos, entre otros. 
2) Seres vivos, bióticos, animados u orgánicos. Son aquellos que tienen vida y que se caracterizan fundamentalmente por la capacidad de reproducirse. A esta categoría de seres vivos pertenecen: las plantas, los animales, los microorganismos (hongos microscópicos, bacterias, virus) y los seres humanos.

En la figura No 01: modelo input-output para el uso del medio ambiente, se observa los inputs y outputs ambientales. Los inputs son la energía, tierra y materias primas (también los residuos reciclados o reutilizados), y los outputs, los efluentes líquidos, las emisiones al aire y los residuos, que contribuyen al agravamiento de problemas ambientales como la destrucción de la capa de ozono, la acidificación, la eutrofización, la dispersión de toxinas, la pérdida de biodiversidad, etc. Todos los indicadores ambientales se restringen a presiones directas ${ }^{10}$.

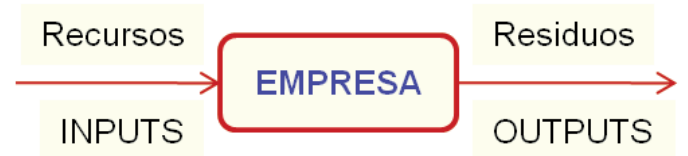

Figura No 01: Modelo input-output para el uso del medio ambiente.

\section{Derecho a gozar de un ambiente saludable}

Desde hace poco menos de dos décadas ha surgido en el mundo un nuevo derecho: el derecho del ambiente. El derecho a gozar de un ambiente saludable, es uno de los llamados derechos humanos de tercera gene- ración $^{11}$, como lo son el derecho a la paz, al desarrollo y al patrimonio común de la humanidad. Todos son denominados también derechos de solidaridad.

En definitiva, este derecho a un ambiente saludable se vincula indisolublemente con los derechos a la vida y a la salud, por ello la protección de este derecho humano comprende aquellos valores que han sido tradicionalmente objeto de tutela jurídica por otros principios o cuerpos normativos.

El derecho humano fundamental a vivir en un ambiente mundialmente sano, debe ser considerado como un requisito y fundamento para el ejercicio de los restantes derechos humanos económicos y políticos. Es necesario reconocer desde el derecho internacional que un ambiente sano es condición sine qua non de la propia vida y que ningún derecho podría ser ejercido en un ambiente degradado. Un razonable nivel de calidad ambiental es un valor esencial para asegurar la supervivencia no solamente humana sino de toda la biosfera.

\section{Contenido constitucional del derecho a un ambiente sano, equilibrado y adecuado}

La segunda parte del Art. 2, inciso 22) de la Constitución Política del Perú dispone que toda persona tenga derecho a gozar de un ambiente equilibrado y adecuado al desarrollo de su vida.

De acuerdo con el Tribunal Constitucio$\mathrm{nal}^{12}$ :

10 LABANDEIRA Xavier - LEÓN Carmelo J. - VÁSQUEZ Xosé, Economía Ambiental, Obra citada, páginas 328-329.

11 Los derechos llamados de primera generación corresponden a las libertades individuales (a la vida, a la libertad, a la privacidad, a la libre expresión, a no ser esclavizado ni torturado), mientras que los denominados de segunda generación conciernen al derecho al trabajo, a una justa remuneración, a la seguridad social, y los derechos colectivos en las esferas social y económica (derecho de los pueblos a la autodeterminación, a la libre disposición de sus recursos naturales, a no ser privados de los medios de subsistencia).

12 Sentencia del Tribunal Constitucional EXP. Nº048-2004-AI/TC. F.J. 17. Del 01/04/2005. Demanda de inconstitucionalidad interpuesta, en representación de más de cinco mil ciudadanos, contra los artículos $1^{\circ}, 2^{\circ}, 3^{\circ}, 4^{\circ}$ y $5^{\circ}$ de la Ley $\mathrm{N}^{\circ}$ 28258 -Ley de Regalía Minera. 
"El contenido del derecho fundamental a un medio ambiente equilibrado y adecuado para el desarrollo de la persona humana está determinado por los siguientes elementos, a saber: 1) el derecho a gozar de ese medio ambiente, 2) el derecho a que ese medio ambiente, se preserve. En su primera manifestación, esto es, el derecho a gozar de un medio ambiente equilibrado y adecuado, dicho derecho comporta la facultad de las personas de poder disfrutar de un medio ambiente en el que sus elementos se desarrollan e interrelacionan de manera natural y armónica; $y$, en el caso en que el hombre intervenga, no debe suponer una alteración sustantiva de la interrelación que existe entre los elementos del medio ambiente. Esto supone, por tanto, el disfrute no de cualquier entorno, sino únicamente del adecuado para el desarrollo de la persona y de su dignidad (artículo $1^{\circ}$ de la Constitución). De lo contrario, su goce se vería frustrado y el derecho quedaría, así, carente de contenido.

Pero también el derecho en análisis se concretiza en el derecho a que el medio ambiente se preserve. El derecho a la preservación de un medio ambiente sano y equilibrado entraña obligaciones ineludibles, para los poderes públicos, de mantener los bienes ambientales en las condiciones adecuadas para su disfrute. A juicio de este Tribunal, tal obligación alcanza también a los particulares, y con mayor razón a aquellos cuyas actividades económicas inciden, directa o indirectamente, en el medio ambiente".

Para Luis Castillo Córdova ${ }^{13}$ este derecho viene justificado en cuanto se trata de una traducción jurídica de una exigencia de la naturaleza humana: la existencia digna de la persona humana exige como presupuesto material necesario, un medio natural adecuado al logro del pleno desarrollo como sujeto con una dignidad que es. Como ha afirmado el Tribunal Constitucional, "En el Estado democrático de derecho de nuestro tiempo ya no sólo se trata de garantizar la existencia de la persona o cualquiera de los demás derechos que en su condición de ser humano le son reconocidos, sino también de protegerla de los ataques al medio ambiente en el que esa existencia de desenvuelve, a fin de permitir que su vida se desarrolle en condiciones ambientales aceptables”.

En concordancia, el artículo I del Título Preliminar del Código del Medio Ambiente prevé que toda persona tiene el derecho irrenunciable a gozar de un ambiente equilibrado, saludable, ecológicamente equilibrado y adecuado para el desarrollo de la vida, y a la preservación del paisaje y la naturaleza.

\section{IMPACTO DEL CRECIMIENTO DE- MOGRÁFICO Y LAS ACTIVIDADES ECONÓMICAS EN EL AMBIENTE}

La actual crisis ambiental se debe a diversos factores como la superpoblación humana que actualmente supera los 6,600 millones y la envergadura de todas las actividades económicas, los cuales vienen ocasionando impactos negativos en el ambiente, deteriorándolo y afectando significativamente la calidad de vida y poniendo en peligro la existencia de las generaciones futuras. Ello se agudiza, si se toma en cuenta los niveles de pobreza que sufre gran parte del mundo ${ }^{14}$.

Los niveles de pobreza que alimentan los problemas ambientales se explican también por el desbalance de la distribución demo-

13 CASTILlO CÓRDOVA Luis. Proceso de Amparo. Código Procesal Constitucional Comentado; Editorial Adrus S.R.L., 1116 páginas, Arequipa 2009, páginas 442-443.

14 Según las estadísticas del Programa de Población, Salud y Medio Ambiente, más de 3,000 millones de personas viven con menos de dos dólares al día. 
gráfica, ya que en los países más ricos reside sólo el $20 \%$ de la población mundial; agravándose por el desbalance mundial en los ingresos y consumo, pues este $20 \%$ más rico representa más del $86 \%$ del consumo privado, mientras que el $20 \%$ más pobre de la población del mundo representa menos del $2 \%$ del total del consumo privado ${ }^{15}$.

En esa perspectiva, el tema ambiental, ha pasado a ser la prioridad de muchos países, el mismo que exige encontrar el equilibrio entre producción-consumo y preservaciónconservación del medio ambiente. Toda actividad económica causa algún tipo de contaminación, por lo que resulta imposible suprimir dichas actividades, ya que éstas conllevan al crecimiento y desarrollo económico. Es necesario encontrar equilibrios justos y el menor impacto negativo en el ambiente.

Jeffrey Sachs ${ }^{16}$, director del Instituto de la Tierra de la Universidad de Columbia y profesor de desarrollo sostenible y de gestión y política sanitaria en esa misma universidad, sostiene que estamos aprendiendo muy deprisa que el crecimiento de la economía mundial no es un motivo de satisfacción absoluta. La envergadura de la actividad económica (que se ha multiplicado por ocho desde 1950 arrojando la asombrosa cifra de 60 billones de dólares anuales de producción) está destruyendo el medio ambiente a una escala sin precedentes en cualquier etapa anterior de la historia de la humanidad. Para abastecernos de alimentos, la actividad económica se basa enormemente en el aprovechamiento de recursos naturales (sobrexplotación de los recursos naturales) y flujos físicos como la lluvia, las corrientes fluviales y, por supuesto, la fotosíntesis. Sin embargo, con el increí- ble aumento de la población y de la renta per cápita, prácticamente todos los ecosistemas importantes del mundo se encuentran hoy en día amenazados por la actividad humana. Dicho en pocas palabras: estamos más cerca que nunca unos de otros, apretujados en una sociedad interconectada de comercio, migraciones, ideas y sí, riesgos de enfermedades epidémicas, terrorismo, movimientos de refugiados y conflictos, todos ellos a escala global.

En la tabla No 01, se presentan datos sobre el Producto Bruto Interno (PBI) de diversos países expresado en dólares anuales, correspondientes al año 2010:

Tabla No 01: Producto Bruto Interno a nivel mundial

(Expresado en billones de US \$)

\begin{tabular}{|l|c|}
\hline \multicolumn{1}{|c|}{ País } & PBI (estimado 2010) \\
\hline Japón & 5272,943 \\
\hline EEUU & 14799,564 \\
\hline China & 5364,869 \\
\hline Francia & 2745,486 \\
\hline Reino Unido & 2353,033 \\
\hline Rusia & 1363,979 \\
\hline India & 1367,216 \\
\hline Brasil & 1910,495 \\
\hline México & 995,918 \\
\hline Perú & 202,295 \\
\hline Chile & 196,451 \\
\hline Argentina & 344,143 \\
\hline
\end{tabular}

Fuente: Fondo Monetario Internacional.

Así también, es útil conocer cuál es la participación que tiene un país en el gran mercado global. Una forma de hacerlo es dividir el PBI de cada país entre el PBI mundial. La siguiente tabla muestra este ratio:

15 ANDALUZ WESTREICHER Carlos, Manual de Derecho Ambiental, Obra citada, página 49.

16 SACHS Jeffrey, Economía para un planeta abarrotado; Editorial Sudamericana S.A., 527 páginas, Argentina 2008, páginas 34-43. 
Tabla No 02: Representatividad en el PBI mundial

\begin{tabular}{|c|c|c|}
\hline \multirow{2}{*}{ País } & \multicolumn{2}{|c|}{ PBI del país / PBI mundial } \\
\cline { 2 - 3 } & $\mathbf{2 0 0 8}$ & $\mathbf{2 0 1 4}$ (estimado) \\
\hline Japón & $8.1 \%$ & $7.81 \%$ \\
\hline EEUU & $23.5 \%$ & $23.3 \%$ \\
\hline China & $7.3 \%$ & $11.1 \%$ \\
\hline Brasil & $2.6 \%$ & $2.8 \%$ \\
\hline Perú & $0.2 \%$ & $0.22 \%$ \\
\hline
\end{tabular}

Fuente: Fondo Monetario Internacional.

De acuerdo con esta información, casi un cuarto de la producción mundial se realiza en Estados Unidos y cerca de 1/12 en Japón ${ }^{17}$.

Un rasgo económico básico es que todavía se producirá mucho más crecimiento económico, no sólo porque la población mundial continuará aumentando sino, lo que es más importante, porque la renta per cápita continuará ascendiendo. La población mundial se ha incrementado en más de 4,000 millones de personas desde 1950, tras pasar de 2,500 millones de habitantes a los 6,600 millones (año 2007). El pronóstico intermedio, llamado a ser el más probable, prevé que la población mundial pasará de los 6,600 millones del año 2007 a 9,200 millones en el año 2050. Por ello, el objetivo debería ser estabilizar la población mundial en 8,000 millones de personas a mediados del siglo XXI.

El líder tecnológico en la actualidad, EEUU, mantiene un media de crecimiento anual en términos de renta per cápita del $1.7 \%$. A continuación se puede apreciar el PBI per cápita de diversos países, expresado en dólares anuales, correspondiente al año 2010 (Tabla No 3).

Pese a considerarse al $\mathrm{PBI}$ per cápita como un indicador del bienestar económico,
Tabla No 03: Producto Bruto Interno per cápita (Expresado en US \$ anuales)

\begin{tabular}{|l|c|}
\hline País & $\begin{array}{c}\text { PBI per cápita } \\
\text { (estimado 2010) }\end{array}$ \\
\hline Japón & 41366 \\
\hline EEUU & 47890 \\
\hline China & $3999\left(^{*}\right)$ \\
\hline Francia & 43634 \\
\hline Reino Unido & 38112 \\
\hline Rusia & 9717 \\
\hline India & 1697 \\
\hline Brasil & 9886 \\
\hline México & 8788 \\
\hline Perú & 6866 \\
\hline Chile & 11492 \\
\hline Argentina & 8493 \\
\hline
\end{tabular}

$\left({ }^{*}\right)$ Corresponde al año 2009.

Fuente: Fondo Monetario Internacional

es necesario precisar algunos de los inconvenientes que presenta:

- No toma en cuenta las diferencias en la distribución del ingreso entre países. Por ejemplo, países como los del Medio Oriente tienen ingresos per cápita muy altos, sin embargo, debido a la desigual distribución del ingreso, el nivel de vida es relativamente bajo.

- Tiende a subestimar el nivel de vida de la población en países en que la producción para el autoconsumo es una parte importante del total producido, como es el caso de las sociedades agrícolas.

- No considera factores como la conservación del medio ambiente o el aprovechamiento sostenible de los recursos naturales renovables y no renovables. Por ejemplo, si un país aumenta su nivel de producción a costa del deterioro permanente del medio ambiente o explota en forma indiscriminada los recursos natu-

17 Muchos ecologistas -extremos- afirman que, de hecho, estamos condenados a reducir consecuentemente el crecimiento económico y que lo mejor que podemos hacer es gestionar una reducción ordenada y equitativa de la renta per cápita. 
rales no renovables, entonces este país se descapitalizaría, debido a que perdería los ingresos que esos recursos pueden generar en el futuro.

El mundo afronta gravísimos problemas ecológicos y medioambientales, pero el agotamiento de los recursos naturales no es el modo correcto de definir la amenaza. La tierra dispone de la energía, la superficie de cultivo, la biodiversidad y los recursos hídricos necesarios para alimentar a la humanidad y sustentar la prosperidad económica para todos en el largo plazo. El problema es que el mercado tal vez no conduzca a su aprovechamiento prudente y sostenible.

\section{CICLO DEL CARBONO}

El carbono (C) es elemento básico en la formación de las moléculas de carbohidratos, lípidos, proteínas y ácidos nucleicos, pues todas las moléculas orgánicas están formadas por cadenas de carbonos enlazados entre sí. La reserva fundamental de carbono, en moléculas de dióxido de carbono $\left(\mathrm{CO}_{2}\right)$ que los seres vivos puedan asimilar, es la atmósfera y la hidrósfera.

En nuestro dinámico planeta, el carbono es capaz de moverse de un medio a otro como parte del ciclo de carbono.

El ciclo del carbono es fundamental, porque de él depende la producción de materia orgánica, que es el alimento básico de todos los seres vivos. De acuerdo con Antonio Brack y Cecilia Mendiola ${ }^{18}$, el ciclo del carbono consiste en un proceso muy complicado, cuyos elementos principales son los siguientes:

- El carbono se encuentra almacenado en el aire, agua y suelo en forma de un gas llamado dióxido de carbono $\left(\mathrm{CO}_{2}\right)$. En el aire está presente como gas; en el agua en forma disuelta. Se encuentra disponible en cantidades abundantes.

- Las plantas toman el carbono del $\mathrm{CO}_{2}$ del agua (plantas acuáticas), del aire o del suelo (plantas terrestres) y con la energía de la luz del sol producen alimentos (glucosa, sacarosa, almidón, celulosa, etc), y liberan oxígeno $\left(\mathrm{O}_{2}\right)$ al aire, al agua o al suelo. Este proceso se denomina fotosíntesis. En el ciclo del carbono las plantas juegan un rol más importante y una gran parte de la masa de las plantas está conformada por compuestos de carbono: azúcares, almidones, celulosa, madera o lignina y compuestos diversos.

- Los animales herbívoros se alimentan de las plantas y usan los compuestos orgánicos para vivir y formar su propia materia. Los carbohidratos (azúcares, almidón, celulosa, lignina, etc.) son descompuestos por los herbívoros por procesos químicos en las células y forman el combustible de su cuerpo. Este proceso se inicia con la respiración, o sea la toma de oxígeno del aire o del agua. Con el oxígeno se descomponen los azúcares y se emite $\mathrm{CO}_{2}$ al aire o al agua, con producción de diversas formas de energía, especialmente calor. Entre los principales animales herbívoros: los que comen hojas (foliófagos); frutos (frugívoros) y madera (xilófagos). Para digerir las partes de las plantas estos herbívoros tienen aparatos digestivos especialmente adaptados.

- Los animales carnívoros toman la materia de otros animales por la alimentación. Absorben los componentes de los animales por el proceso digestivo y los descomponen en las células con ayuda del oxígeno que respiran (del aire o del

18 BRACK EGG Antonio - MENDIOLA VARGAS Cecilia, Ecología del Perú; Segunda Edición, Editorial Bruño, 495 páginas, Lima 2004, páginas 60-61. 
agua) y emiten $\mathrm{CO}_{2}$ al aire o al agua. Entre los tipos de carnívoros especializados: los que comen zooplancton o animales microscópicos del agua se denominan zooplanctívoros; los que comen insectos se denominan insectívoros; los que comen peces se denominan piscívoros, etc.

- La descomposición de las plantas y los animales al morir restituye el carbono al medio en forma de $\mathrm{CO}_{2} \mathrm{y}$ materia orgánica, que son aprovechados por otras plantas para reiniciar el ciclo. Los organismos vivos, que se encargan de la descomposición, proceso también denominado putrefacción, se denomina detritívoros y están conformados esencialmente por bacterias y hongos.

\section{Efecto invernadero}

Hecho ocasionado por la absorción en la atmósfera terrestre de las radiaciones infrarrojas emitidas por la superficie impidiendo que escapen al espacio exterior y aumentado así la temperatura media del planeta.

En la figura No 03: Efecto invernadero, se puede apreciar que la atmósfera terrestre en general acumula el calor, reteniendo las radiaciones caloríficas desde la tierra al espacio. El $\mathrm{CO}_{2}$ y el vapor del agua, que representan una fracción muy pequeña en la composición de la atmósfera, ejercen una influencia muy importante en el balance de calor entre la atmósfera y la tierra. Ambas sustancias dejan pasar la radiación solar de onda corta, pero
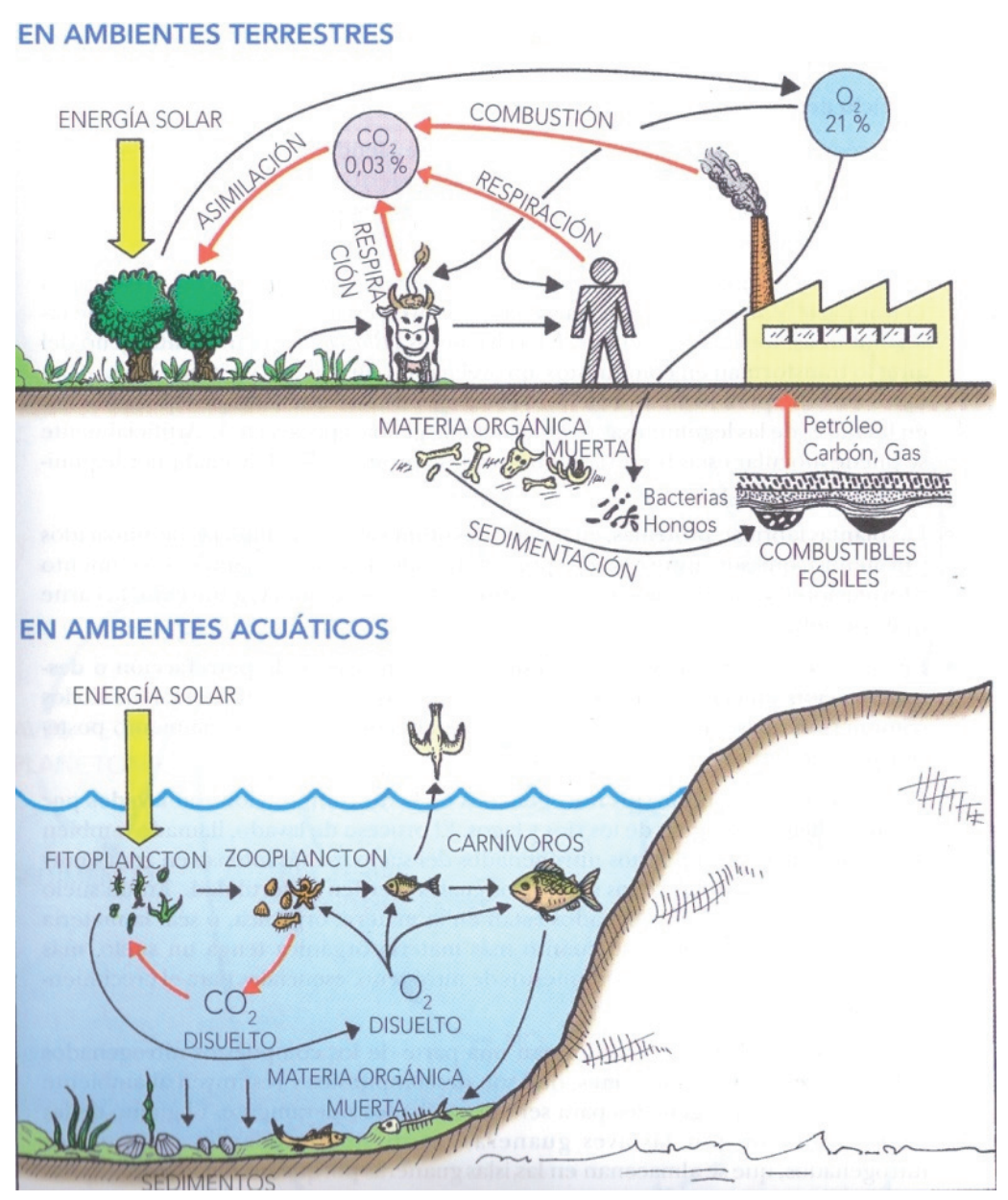

Fuente: BRACK EGG Antonio - MENDIOLA VARGAS Cecilia. En Ecología del Perú.

Figura No 02: Ciclo del carbono 


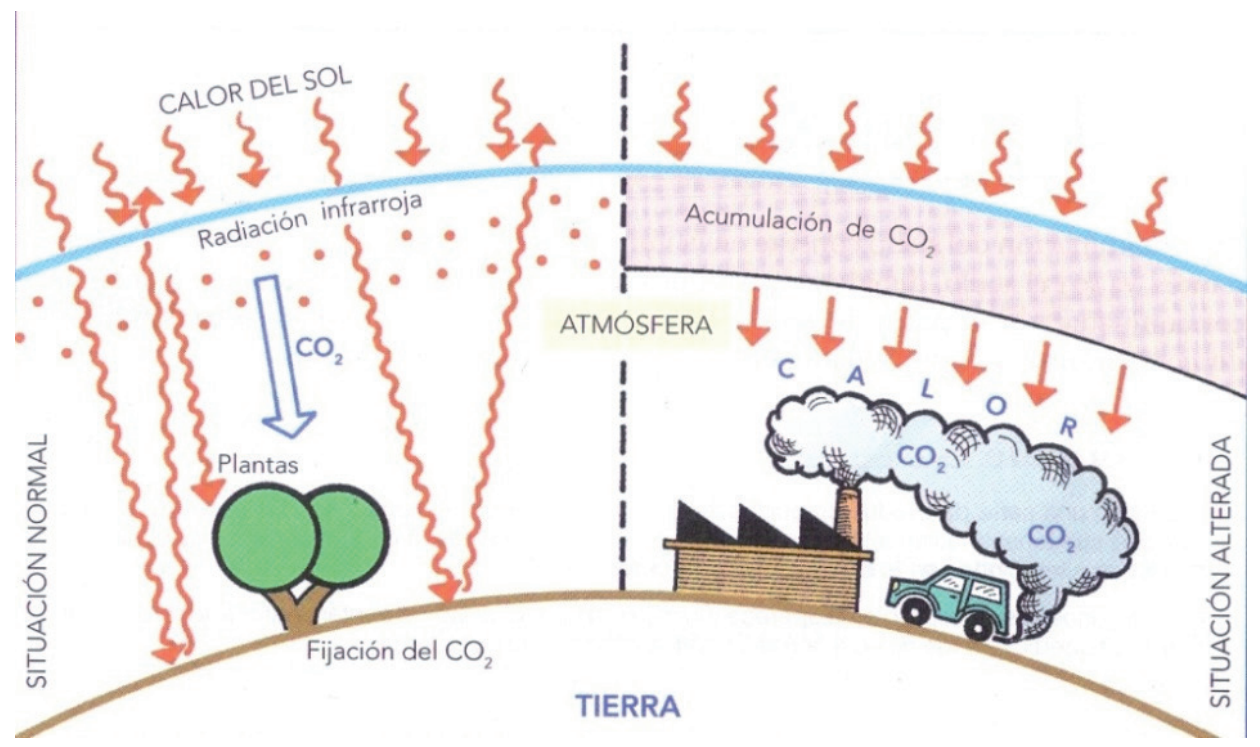

Fuente: BRACK EGG Antonio - MENDIOLA VARGAS Cecilia. En Ecología del Perú.

Figura No 03: Efecto invernadero

son absorbentes de las longitudes de ondas reflejadas o emitidas desde la tierra hacia el espacio. Es por eso que producen un efecto de calentamiento global, conocido como el efecto invernadero, similar a las instalaciones cubiertas de vidrio para cultivar plantas en los climas fríos.

\section{Gases de efecto invernadero (GEI)}

El Convenio Marco de las Naciones Unidas sobre el Cambio Climático (CMNUCC) establece que por "gases de efecto invernadero" se entiende aquellos componentes gaseosos de la atmósfera, tanto naturales como antropógenos, que absorben y reemiten radiación infrarroja.

Entre los gases responsables de efecto invernadero (GEI) que son parte de la composición normal de la atmósfera se encuentran: $\checkmark$ Dióxido de carbono $\left(\mathrm{CO}_{2}\right)$.

$\checkmark$ Metano $\left(\mathrm{CH}_{4}\right)$.

$\checkmark$ Vapor de agua $\left(\mathrm{H}_{2} \mathrm{O}\right)$.

$\checkmark$ Óxidos de nitrógeno (NOx).

$\checkmark$ Clorofluorocarbonos (CFC) y algunos otros gases (gases fluorinados, concretamente el hexafluoruro de azufre, los compuestos hidrofluorocarbonados o HFC, y los compuestos perfluorocarbonados o PFC).

Todos ellos se denominan gases de efecto invernadero, y su concentración cada vez mayor en la atmósfera es la causa del cambio climático antropógeno. Cada GEI presenta una diferente capacidad de atrapar calor en la atmósfera.

El dióxido de carbono $\left(\mathrm{CO}_{2}\right)$ es un gas incoloro, inoloro y con un sabor ácido presente en forma natural en la atmósfera de la Tierra ${ }^{19}$. Es el gas de efecto invernadero más

19 La estructura molecular del dióxido de carbono está compuesta de un átomo de carbono unido a dos átomos de oxígeno; según la nomenclatura química: $\mathrm{CO}_{2}$. Su densidad es, más o menos, 1,5 veces más densa que el aire y se disuelve en el agua en una proporción de un 0,9 de volumen del gas por volumen de agua, siempre a 20 grados centígrados. $\mathrm{El} \mathrm{CO}_{2}$ ha estado siempre presente en la naturaleza y es imprescindible para su equilibrio, el cual, se consigue a través del llamado "ciclo del carbono”, donde, durante un largo período, se producen, en un proceso biogeoquímico, una serie de transformaciones del $\mathrm{CO}_{2}$ esenciales para la regulación del clima y la vida en la Tierra. 
importante de los que hoy día alteran la climatología de la Tierra ${ }^{20}$. Antes de la era industrial, durante centenares de miles de años el nivel de $\mathrm{CO}_{2}$ de la atmósfera era del orden de 280 moléculas por millón de moléculas de aire ${ }^{21}$.

Un aumento desmedido del dióxido de carbono en la atmósfera, variando la concentración normal de este gas, podría ocasionar que la temperatura media de la tierra se eleve, lo que tendría como consecuencia cambios climáticos y las consecuencias podrían ser devastadoras: deshielo de los polos y elevación del nivel de los océanos. Por ello, en la actualidad existen diversas formas para reducir las emisiones de $\mathrm{CO}_{2}$ a la atmósfera:

a. Recaptura del carbono a través de la reforestación. Para lo cual es necesario conservar los bosques.

b. Captura y secuestro de carbono $(\mathrm{CSC})^{22}$.

$\mathrm{El}$ dióxido de carbono $\left(\mathrm{CO}_{2}\right)$ tiene un ciclo natural muy complejo. En el transcurso de todo un año, los árboles absorben el dióxido de carbono atmosférico en la fotosintesis $^{23}$ con el fin de producir carbohidratos, mientras que los animales descomponedores digieren los carbohidratos (por ejemplo, de las hojas caídas) y devuelven el dióxido de carbono al aire. A escala geológica, el dióxido de carbono es emitido a la atmósfera por los volcanes y reabsorbido por los océanos y la corteza terrestre. Pero ahora, en la era industrial, se están liberando ingentes cantidades de dióxido de carbono en el aire mediante la quema de combustibles fósiles ${ }^{24}$, que combinan el carbono de los combustibles con el oxígeno atmosférico para dar lugar al dióxido de carbono y a la liberación de energía. La deforestación, que implica despojar un terreno de plantas forestales, tiene más o menos el mismo efecto que quemar combustibles fósiles, ya que convierte el carbono de los árboles y las plantas en dióxido de carbono atmosférico.

El incremento del $\mathrm{CO}_{2}$ se debe a la industrialización, el consumo de grandes cantidades de combustibles fósiles (petróleo, gas, carbón) y por descomposición de la inmensa cantidad de materia orgánica contenida en los bosques, que han sido aceleradamente destruidos (tala, quema).

El metano $\left(\mathbf{C H}_{4}\right)$ es otro gas del efecto invernadero sobre el que la actividad humana ejerce mucha influencia. Las emisiones de metano son obra principalmente de las bacterias que digieren los compuestos de carbono $y$ producen metano en tres lugares esenciales: los arrozales de tierras anegadas, los estómagos del ganado, que emiten metano tanto en sus eructos como por el otro extremo del aparato digestivo y los vertederos orgánicos.

El vapor del agua $\left(\mathrm{H}_{2} \mathrm{O}\right)$ es otro gas del efecto invernadero en aumento, como consecuencia del mecanismo de retroalimentación positiva ocasionado por el incremento de dióxido de carbono. El aire más caliente retiene más vapor de agua; el vapor de agua

20 El dióxido de carbono $\mathrm{CO}_{2}$ representa aproximadamente el $80 \%$ del total de las emisiones causantes del efecto invernadero y por tanto, debe ocupar la atención de las políticas ambientales correctivas.

$21 \mathrm{Si}$ el nivel de $\mathrm{CO}_{2}$ de la atmósfera era del orden de 280 moléculas por millón de moléculas de aire, por lo general también se puede expresar como "280 partes por millón" o "ppm".

22 Véase el acápite captura y secuestro de carbono.

23 La fotosíntesis es el proceso mediante el cual las plantas verdes combinan el dióxido de carbono de la atmósfera con el agua y producen materia vegetal, emitiendo oxígeno al ambiente. A partir de ésta se produce prácticamente toda la materia orgánica de nuestro planeta y se garantiza toda la alimentación de los seres vivos.

24 Compuesto de carbono e hidrógeno en diferentes proporciones, por ejemplo el carbón en su mayor parte carbono con una pequeña parte de hidrógeno y otras impurezas, así como el petróleo y el gas natural. 
es en sí mismo un gas de efecto invernadero y, por tanto, calienta aún más el mundo. El resultado es que, con el aumento del vapor de agua en la atmósfera, el calentamiento originado por un aumento de dióxido de carbono, inducido por el ser humano se amplifica enormemente.

El óxido nitroso $\left(\mathrm{N}_{2} \mathrm{O}\right)$ también es otro gas del efecto invernadero que resulta de la utilización por parte de los seres humanos de fertilizantes sobre la base de nitrógeno. Antonio Brack y Cecilia Mendiola ${ }^{25}$ sostienen que los principales óxidos de nitrógeno son el óxido nitroso (monóxido de nitrógeno, NO), el óxido nítrico (pentóxido de dinitrógeno), el dióxido de nitrógeno $\left(\mathrm{NO}_{2}\right)$ y el ácido nítrico. El óxido nitroso $\left(\mathrm{N}_{2} \mathrm{O}\right)$ se forma por reacción del nitrógeno atmosférico y del oxígeno en las cámaras de combustión de los motores, a alta temperatura y presión. En las concentraciones en que se produce no es contaminante, pero en el aire se oxida a dióxido de nitrógeno $\left(\mathrm{NO}_{2}\right)$, importante elemento de la niebla fotoquímica que se produce en las grandes ciudades.

Los clorofluorocarbonos $(\text { CFC })^{26}$ son sustancias orgánicas sintéticas derivadas de hidrocarburos del petróleo de bajo peso, también conocidos como haloorgánicos. Fueron introducidos a principios de la década de los años 1930 por ingenieros de General Motors, para sustituir materiales peligrosos como el dióxido de azufre y el amoníaco. Son muy estables al calor, químicamente inertes, y pueden permanecer en el ambiente por muchos años.

La estructura de los CFC posee varias relaciones de flúor y cloro; los CFC son cada uno de los derivados de los hidrocarburos saturados obtenidos mediante la sustitución de átomos de hidrógeno por átomos de flúor y/o cloro. Los más utilizados comercialmente son los freones para producir aerosol.

El problema de los CFC es que no se degradan en la tropósfera, permanecen inalterados por largo tiempo (más de 10 años) y se difunden hasta la estratósfera. Cuando llegan a una altura entre los 20 y $50 \mathrm{~km}$ se descomponen por una reacción fotoquímica, produciendo cloro atómico, que se combina con el ozono $\left(\mathrm{O}_{3}\right)$ y reduce la capa protectora de la atmósfera contra los temibles rayos ultravioleta provenientes del sol. Este fenómeno es conocido como la destrucción de la capa de ozono o el hueco de ozono en aumento sobre la Antártida. Al destruirse la capa de ozono, los rayos ultravioleta pueden pasar hasta la superficie de la tierra y producir alteraciones en los ecosistemas (agua, organismos acuáticos, organismos terrestres) y originar irritaciones en los ojos y cáncer a la piel. El ozono $\left(\mathrm{O}_{3}\right)$, es una sustancia cuya molécula está compuesta por tres átomos de oxígeno, formada al disociarse los 2 átomos que componen el gas de oxígeno. Cada átomo de oxígeno liberado se une a otra molécula de oxígeno $\left(\mathrm{O}_{2}\right)$, formando moléculas de Ozono $\left(\mathrm{O}_{3}\right)$.

A temperatura y presión ambientales el ozono es un gas de olor acre y generalmente incoloro, pero en grandes concentraciones puede volverse ligeramente azulado. $\mathrm{Si}$ se respira en grandes cantidades, es tóxico y puede provocar la muerte.

Por lo tanto, el efecto invernadero se produce porque estos gases concretos (dióxido de carbono, el vapor del agua, el metano, el óxido nitroso, los clorofluorocarbonos, el ozono) actúan como un invernadero: permiten que la radiación solar llegue al planeta pero no dejan escapar el calor resultante.

25 BRACK EGG Antonio - MENDIOLA VARGAS Cecilia, Obra citada, páginas 420-421.

26 BRACK EGG Antonio - MENDIOLA VARGAS Cecilia, Obra citada, página 428. 
Concretamente, los gases de efecto invernadero son transparentes a la radiación ultravioleta (de longitud de onda corta) procedente del sol, que atraviesa la atmósfera e incide en la Tierra. Esta radiación calienta el planeta, que reacciona irradiando al espacio energía infrarroja (de longitud de onda larga). Aquí es donde entran en juego los gases de efecto invernadero. Estos gases atmosféricos absorben parte de la radiación infrarroja desprendida y retienen la energía calorífica en la atmósfera, con lo cual calientan la Tierra ${ }^{27}$.

El hecho más destacado del Antropoce$\mathrm{no}^{28}$ es que los seres humanos ocasionamos un incremento importante de la concentración de gases de efecto invernadero. Estamos alterando una parte fundamental del sistema físico de la Tierra. Cada vez que quemamos combustibles como gasolina, querosene, carbón y gas natural, emitimos a la atmósfera dióxido de carbono $\left(\mathrm{CO}_{2}\right)$ y el efecto invernadero aumenta.

En la última década se ha intensificado el efecto invernadero como consecuencia de los elevados niveles de emisiones de los GEI asociados con las actividades industriales y agrícolas que realiza el hombre, así como también con la deforestación; los cuales limitan la capacidad regenerativa de la atmósfera para eliminar el dióxido de carbono (principal responsable del efecto invernadero). Es así como la temperatura global se incremen- ta sensiblemente con implicancias negativas que este calentamiento pueda tener para la humanidad y el medio físico.

\section{Consecuencias de los gases del efecto invernadero}

Las consecuencias de los gases de efecto invernadero (GEI) se resume en lo que se conoce como calentamiento global. La alteración de la concentración de gases de efecto invernadero en la atmósfera modifica no sólo las temperaturas, sino también muchos otros procesos químicos, climáticos y biológicos del planeta Tierra.

Los denominados GEI, precursores del cambio climático, surgen fundamentalmente de la quema de combustibles fósiles y su emisión tiene por tanto una naturaleza humana.

Cabe precisar que el principal efecto es el incremento progresivo de la temperatura promedio $^{29}$. En ese sentido, el cambio climático $^{30}$ es la mayor amenaza ambiental del siglo XXI, que podría provocar una catástrofe repentina de grandes dimensiones. Todos los agentes económicos sin excepción, las economías y la naturaleza en todo el mundo están siendo afectadas.

Entre las principales consecuencias se pueden mencionar:

1. Aumentos considerables de las temperaturas medias.

27 SACHS Jeffrey, Economía para un planeta abarrotado; Obra citada, página 122.

28 Paul Crutzen, químico holandés, ganador del Premio Nóbel de Química en 1995 por sus investigaciones sobre la incidencia del ozono en la atmósfera, ha calificado a nuestro tiempo como el Antropoceno, una era en que la Tierra está dominada por el ser humano, porque el volumen de las actividades humanas es ahora tan grande que ha desbaratado todos los sistemas fundamentales para el sostenimiento de la vida.

29 Los registros meteorológicos indican que desde 1850 la temperatura de la Tierra ya ha experimentado un incremento medio de 0.8 grados centígrados (ó 1.4 grados Farenheit). La Tierra reacciona más deprisa aumentando su temperatura como consecuencia del incremento de los gases de efecto invernadero, mientras que la temperatura de los océanos aumenta en un intervalo mucho mayor, fenómeno conocido como inercia térmica.

30 El cambio climático es un fenómeno ambiental originado por la concentración atmosférica de un conjunto de gases cuya presencia genera una especie de efecto invernadero. El Convenio Marco de las Naciones Unidas sobre el Cambio Climático (CMNUCC) establece que por "cambio climático" se entiende un cambio de clima atribuido directa o indirectamente a la actividad humana que altera la composición de la atmósfera mundial y que se suma a la varibilidad natural del clima observada durante períodos de tiemp comparables. 
2. Incremento significativo de la variabilidad climática (inundaciones, sequías, etc.).

3. Elevación del nivel de los océanos y esencialmente la química oceánica.

4. Destrucción del hábitat, ocasionando desplazamientos de las especies hacia altitudes o latitudes más frías, buscando los climas a los que están habituados. Aquellas especies que no sean capaces de adaptarse ni desplazarse se extinguirán.

5. Aumento y propagación de enfermedades infecciosas.

6. Alteraciones de la actividad agraria, sobre todo en la productividad agrícola.

7. Alteraciones de la disponibilidad de agua.

8. Aumento de los riesgos naturales, alterando la frecuencia e intensidad de los fenómenos meteorológicos extremos.

\section{Dimensiones del efecto invernadero}

Hay tres dimensiones que se deben tomar en cuenta cuando nos fijamos en las emisiones de gases de efecto invernadero ${ }^{31}$.

1. El flujo de dichas emisiones, que es la cantidad de gas emitido anualmente.

2. La absorción neta de dichas emisiones en la atmósfera. Cuando se emite dióxido de carbono, una parte es asimilado por la Tierra en forma de materia vegetal y dióxido de carbono del suelo y otra parte se disuelve al océano. En la actualidad, aproximadamente la mitad de las emisiones acaban en la atmósfera.

3. La tercera dimensión es la única que determina el efecto invernadero: la concentración de dichos gases en la atmósfera. Cuando se registran todos estos datos (las emisiones, la absorción en la atmósfera frente a la producida en la tierra y el océano y la concentración en la atmósfera) hablamos de balance de gases de efecto invernadero.

Según cifras del año 2007, se emiten cada año unos 36,000 millones de toneladas (o gigatoneladas) de dióxido de carbono. De ellas, aproximadamente la mitad, unos 17,000 millones de toneladas, van a parar a la atmósfera, y el resto lo absorben los sumideros naturales de la tierra y el océano ${ }^{32}$. El aumento anual de 17,000 millones de toneladas se traduce en un incremento de la concentración de dióxido de carbono en la atmósfera.

A diferencia de las $280 \mathrm{ppm}$ de la era pre industrial, en la actualidad la concentración de carbono en la atmósfera es de 380 ppm. Este incremento de $100 \mathrm{ppm}$ es fruto de la deforestación y la quema de combustibles fósiles. En definitiva, si el mundo continúa con su actual tasa de emisiones, que está produciendo un incremento anual de más o menos 2 ppm, la concentración de carbono pasaría de las $380 \mathrm{ppm}$ actuales a $580 \mathrm{ppm}$ en noventa años (finales del siglo XXI).

\section{GESTIÓN DEL CARBONO}

En la actualidad el mundo se enfrenta a un desafío novedoso y preocupante: la gestión del carbono. El dióxido de carbono es el gas de efecto invernadero más importante de los que hoy día altera la climatología de la Tierra. La problemática del balance global del carbono es que todos y cada uno de nosotros en este planeta participamos en el ciclo del carbono, ya sea conduciendo un automóvil, utilizando electricidad produci-

31 SACHS Jeffrey, Economía para un planeta abarrotado; Obra citada, página 133.

32 El Convenio Marco de las Naciones Unidas sobre el Cambio Climático (CMNUCC) establece que por "sumidero" se entiende cualquier proceso, actividad o mecanismo que absorbe un gas de efecto invernadero, un aerosol o un precursor de un gas de efecto invernadero de la atmósfera. 
da mediante combustibles fósiles (petróleo, gas), ingiriendo alimentos o mediante la descomposición de la inmensa cantidad de materia orgánica contenida en los bosques que fueron destruidos (tala, quema), etc.

Las perturbaciones al balance global del carbono se enmarcan dentro de un contexto más amplio conocido como «el cambio ambiental global», que amenaza de diversas formas el funcionamiento del planeta e incluye varios fenómenos y procesos íntimamente relacionados. Un cambio global se define a partir de dos tipos de fenómenos:

i. Aquellos que alteran las capas de fluídos del sistema de la Tierra (la atmósfera o los océanos), y que, por lo tanto, es experimentado a escala planetaria. Ejemplos: cambio en la composición de la atmósfera (aumentos en la concentración de bióxido de carbono y de metano), el cambio climático, la destrucción de la capa de ozono en la estratósfera y el aumento de la incidencia de radiación ultravioleta.

ii. Aquellos que ocurren en lugares discretos pero tan ampliamente distribuidos que constituye un cambio global. Ejemplos: pérdida de la biodiversidad, el cambio en el uso del suelo (destrucción de los bosques para uso agropecuario), los cambios en la química atmosférica (lluvia ácida ${ }^{33}$ y aumento en la concentración de ozono en la tropósfera) y las invasiones biológicas.

\section{Importancia de la gestión del carbono}

El denominador común de todos los componentes del cambio ambiental global es el ser humano y sus actividades, que han adquirido enormes proporciones con relación a los flujos de energía y materiales en el nivel global.

La existencia e importancia de los fenómenos de cambio climático es, en la actualidad, un hecho comúnmente aceptado por la comunidad científica. Sabemos que el cambio climático es un problema causado fundamentalmente por las emisiones de origen humano de GEI, entre las que destaca por su peso relativo el dióxido de carbono. Puesto que la emisión de buena parte de los GEI está íntimamente relacionada con la quema de combustibles fósiles, una solución del problema a corto plazo es prácticamente imposible y las implicaciones sociales y económicas de las políticas diseñadas para su control son muy importantes ${ }^{34}$.

Por ello resulta primordial gestionar el balance global de carbono a fin de que la concentración de dióxido de carbono en la atmósfera se mantenga en niveles de seguridad, y así evitar aproximarnos a umbrales peligrosos que podrían tener consecuencias catastróficas de grandes magnitudes sobre las sociedades humanas y ecosistemas.

\section{Acciones para gestionar el balance de carbono}

El nivel de consumo concentrado (el 20\% más rico representa más del $86 \%$ del consumo privado, mientras que el $20 \%$ más pobre de la población del mundo representa menos del $2 \%$ del total del consumo privado) explica el desbalance en los niveles de emisiones contaminantes, así por ejemplo, sólo cuatro

\footnotetext{
33 La lluvia ácida es la deposición, seca o húmeda, de sustancias contaminantes atmosféricas de naturaleza ácida. Las emisiones precursoras de la lluvia ácida son principalmente el dióxido de azufre (SO2) y los óxidos de nitrógeno (NOx), originadas fundamentalmente cuando se queman combustibles fósiles..

34 LABANDEIRA Xavier - LEÓN Carmelo J. - VÁSQUEZ Xosé, Economía Ambiental, Obra citada, página 278.
} 
países producen casi la mitad de las emisiones globales de $\mathrm{CO}_{2}$ (Estados Unidos 22.9\%, China $15.1 \%$, Japón 5\% e India 4,4\%) ${ }^{35}$.

La mayor parte de emisiones ${ }^{36}$ de dióxido de carbono se deben a un número reducido de actividades. La tabla siguiente, nos permite apreciar dichas actividades.

Tabla No 04: Emisiones totales de dióxido de carbono en 2007.

(Expresado en gigatoneladas y en porcentaje del total)

\begin{tabular}{|c|c|c|c|}
\hline \multicolumn{2}{|c|}{$\begin{array}{l}\text { Emisiones de dióxido de } \\
\text { carbono }\end{array}$} & GT & $\%$ \\
\hline \multicolumn{2}{|c|}{ 1) Combustibles fósiles } & 29 & $81 \%$ \\
\hline \multirow[t]{5}{*}{ De los cuales: } & Electricidad & 11.5 & $32 \%$ \\
\hline & Industria & 8 & $22 \%$ \\
\hline & Transportes & 6.5 & $18 \%$ \\
\hline & $\begin{array}{l}\text { Usos } \\
\text { residenciales }\end{array}$ & 2 & $6 \%$ \\
\hline & Usos comerciales & 1 & $3 \%$ \\
\hline \multicolumn{2}{|c|}{ 2) Deforestación } & 7 & $19 \%$ \\
\hline \multicolumn{2}{|c|}{ TOTAL } & 36 & $100 \%$ \\
\hline
\end{tabular}

Fuente: Estimaciones de J..5 Sachs basadas en los cálculos de emisiones de combustibles fósiles del año 2005 por la Agencia Internacional de Energía (2007) en "Economía para un planeta abarrotado".

Jeffrey Sach ${ }^{37}$ sostiene que para gestionar el balance de carbono, debemos:

1. Frenaro detener la deforestación. La deforestación es el proceso más fácil de frenar. La mayor parte de la deforestación que se produce tiene poco valor económico. El bosque se tala para crear nuevos pastos, como por ejemplo en el Amazonas; pero se trata de terrenos de baja calidad agrícola y acaban por ser abandonados poco después de la poda de árboles. Con unos incentivos económicos modestos, como el pago a la comunidad local para que se preserve el bosque en lugar de convertirlo en pastos, se pueden superar los débiles incentivos económicos que en la actualidad conducen a la deforestación.

2. Encontrar formas de reducir las emisiones derivadas de la producción de electricidad. Existen algunas vías principales para reducir las emisiones derivadas de los sectores energéticos:

- Incrementar la eficiencia en el consumo de electricidad (mayor beneficio útil por kilovatio/hora).

- Incrementar la proporción de producción de electricidad sobre la base de reservas de energía de combustibles no fósiles (incluidas la eólica, solar, hidráulica, geotérmica, la de los biocombustibles y la nuclear).

a Desarrollar un proceso especial de ingeniería para capturar el dióxido de carbono de las centrales térmicas alimentadas con combustibles fósiles y almacenarlo de forma segura empleando una tecnología denominada captura y secuestro de carbono (CSC).

3. Reducir las emisiones lanzadas por los automóviles. En los últimos tiempos se ha incrementado los kilómetros que se puede recorrer por litro de combustible con la nueva tecnología híbrida que combina la utilización de gasolina con acumuladores eléctricos. Esta tecnología ya duplica aproximadamente los kilómetros por litro de algunos modelos de automóviles. Si los coches híbridos pueden ser conectados también a la red eléctrica, quizá se pueda volver a duplicar la cifra de kilómetros recorridos por litro de combustible. La idea es que un vehículo dependa prin-

35 ANDALUZ WESTREICHER Carlos, Manual de Derecho Ambiental, Obra citada, páginas 49-50.

36 El Convenio Marco de las Naciones Unidas sobre el Cambio Climático (CMNUCC) establece que por "emisiones" se entiende la liberación de gases de efecto invernadero o sus precursores en la atmósfera en un área y un período especificados.

37 SACHS Jeffrey, Economía para un planeta abarrotado; Obra citada, páginas 138-162. 
cipalmente de la energía del acumulador para cubrir aproximadamente los primeros sesenta kilómetros y que lleve una reserva de gasolina para el momento en que la batería se descargue o sea necesario un pico de energía adicional. El coche se recargaría por la noche enchufándolo en un momento del día en que la red eléctrica no soporta picos de consumo. El tema será pasar de la gasolina a electricidad producida por fuentes de energía renovable o centrales eléctricas que capturen y secuestren sus emisiones de carbono.

4. Sanear unos cuantos procesos industriales de primer orden (acero, cemento, refinerías o las petroquímicas). Estos sectores producen la mayoría de las emisiones de carbono de la industria. Similar a lo que sucede con las centrales térmicas, es probable que las fábricas más grandes sean capaces de capturar y secuestrar el dióxido de carbono a un costo reducido y conecten su red de tuberías de evacuación de $\mathrm{CO}_{2}$ a la red de canalización que empleen las centrales térmicas ${ }^{38}$. Muchas fábricas también pueden pasar de quemar carbón y petróleo in situ a utilizar electricidad procedente de la red, lo cual es beneficioso siempre que la electricidad procedente de la red sea producida con bajas emisiones de carbono. Las fábricas también pueden pasar de consumir combustibles fósiles a utilizar en sus propias instalaciones otras alternativas con bajas emisiones de carbono, como la energía solar o las pilas de combustible de hidrógeno (que son beneficiosas siempre que el hidrógeno sea producido en procesos con bajas emisiones de carbono).

5. Diseñar viviendas y los edificios comerciales de forma que se reduzca en ellos la utilización de combustibles fósiles y se economice en términos generales el consumo de energía. Los edificios verdes están concebidos para aprovechar de forma más eficiente la radiación solar (tanto la luz del sol directa como la captada mediante placas solares), reciclar los residuos y el agua, emplear mejores aislamientos y recoger agua de lluvia.

6. Fomentar la eficiencia energética de los edificios, y consumir más eficientemente la energía en las oficinas y en el hogar.

7. Reducir el consumo de electricidad incrementando la eficiencia de los motores, los aparatos, el aislamiento y otros elementos determinantes de la demanda de electricidad.

8. Aumentar las superficies vegetales que actúan como sumideros, es decir, que absorben carbono, evitar la deforestación y aumentar las repoblaciones, especialmente de especies arbustivas.

\section{Captura y secuestro de carbono (CSC)}

La CSC consiste en el desarrollo de un proceso especial de ingeniería para capturar el dióxido de carbono de las centrales térmicas alimentadas con combustibles fósiles (el petróleo, el gas natural y el carbón se denominan así por ser energía almacenada durante millones de años) y almacenarlo de forma segura empleando una tecnología denominada "captura y secuestro de carbono - CSC". Si la CSC es viable, esta tecnología permitirá que el mundo continúe utilizando combustibles fósiles baratos como el carbón de un modo que no desbarate el clima.

Según Jeffrey Sachs ${ }^{39}$, la idea básica de la captura y secuestro de carbono ya está demostrada. Se puede recoger el dióxido de

38 Véase Figura No 04: Diagrama esquemático de posibles sistemas de CSC.

39 SACHS Jeffrey, Economía para un planeta abarrotado; Obra citada, páginas 144-146. 
carbono $\left(\mathrm{CO}_{2}\right)$ de los conductos de escape de una central eléctrica, introducirlos en una tubería y bombearlo al interior de silos de almacenamiento geológico. La totalidad del proceso se muestra en la figura No 04: Diagrama esquemático de posibles sistemas de CSC. La captura se refiere al proceso de recoger el $\mathrm{CO}_{2}$ en el lugar de producción de la electricidad (en la planta petroquímica, en la fábrica de cemento, y así sucesivamente) y secuestrarlo en su almacén geológico. La parte más difícil de este reto es encontrar posibles lugares de almacenamiento que sean lo suficientemente grandes y seguros como para alojar miles de millones de toneladas de $\mathrm{CO}_{2}$ cada año.

Las alternativas de almacenamiento más viables consisten en inyectar el $\mathrm{CO}_{2}$ en reservorios subterráneos, como pozos petrolíferos abandonados, en formaciones geológicas en las que el $\mathrm{CO}_{2}$ reaccionará con los minerales para formar un material sólido estable (como el carbonato de magnesio), en lugares situados bajo el lecho oceánico donde el $\mathrm{CO}_{2}$ adoptaría un estado sólido y se hundiría, o en acuíferos salinos subterráneos, que son zonas que retienen agua salada y son capaces de albergar grandes depósitos de $\mathrm{CO}_{2}$.

Por lo que se refiere a la captura en sí, hay dos posiciones:

1. La idea al uso es que el $\mathrm{CO}_{2}$, debería capturarse en lugar de origen (centrales térmicas, hornos de cemento y hornos de acero), antes de que sea emitido a la atmósfera.

2. Otra alternativa, es capturar directamente el $\mathrm{CO}_{2}$, del aire mediante procesos químicos especiales para, a continuación, secuestrar ese $\mathrm{CO}_{2}$ capturado.

Frente a estas dos alternativas, la mayoría de los ingenieros han dado por sentado que la captura de $\mathrm{CO}_{2}$ en las centrales térmicas y demás grandes instalaciones industriales sería menos costosa que llevarla a cabo directamente del aire. Sin embargo, Klaus Lackner y otros han señalado que la captura directa de $\mathrm{CO}_{2}$ del aire tendría unas ventajas inmensas, ya que lo máximo que se puede conseguir en una central térmica es impedir nuevas emisiones. En cambio, con la captura de aire podríamos revertir lo que hemos hecho hasta este momento.

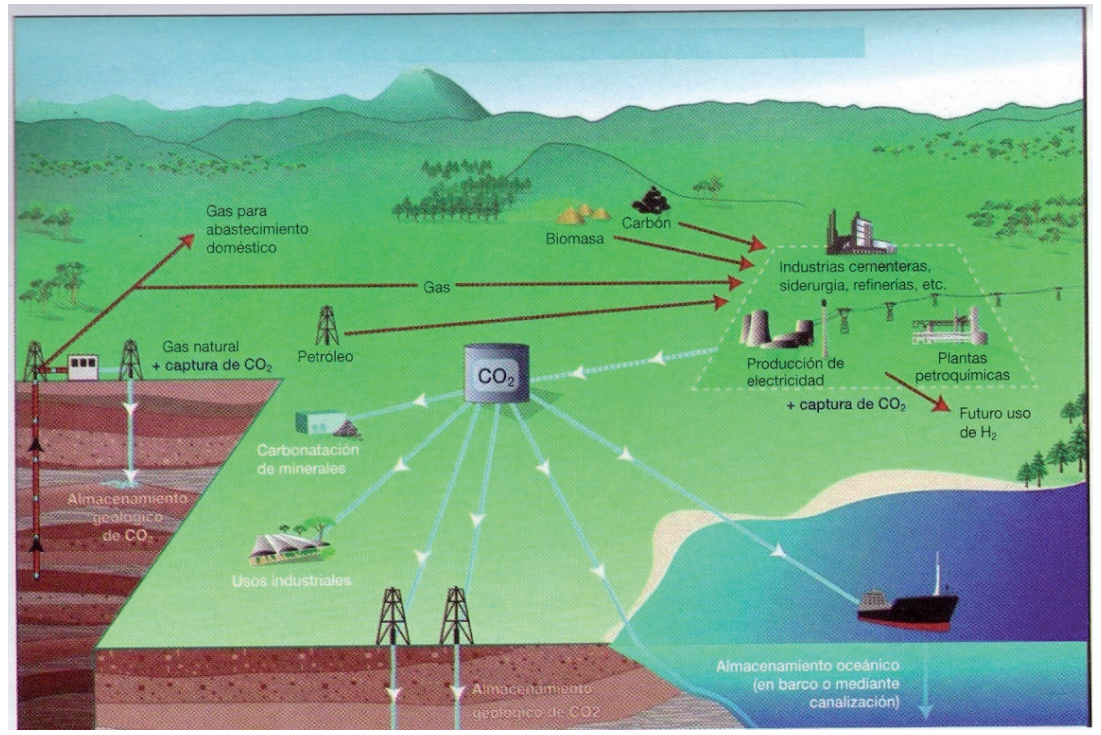

Fuente: IPCC - Intergovernmental Panel on Climate Change (2005). En "Economía para un planeta abarrotado".

Figura No 04: Diagrama esquemático de posibles sistemas de CSC 


\section{BONOS DE CARBONO}

Denominados también bonos verdes y se negocian en los mercados bursátiles como cualquier otro activo. Constituye un mecanismo desarrollado para reducir las emisiones de gases causantes del calentamiento global o efecto invernadero.

Los bonos de carbono son consecuencia del Protocolo de Kyoto ${ }^{40}$ como un modelo de Mecanismo de Desarrollo Limpio, que son proyectos de inversión que favorecen el reemplazo de nuevas tecnologías, limpias, que favorecen al medio ambiente y reducen las emisiones de gases contaminantes del efecto invernadero. Los proyectos pueden realizarse tanto en países desarrollados como en emergentes. En el Protocolo de Kyoto, los países industrializados se comprometieron, para el año 2012, reducir sus emisiones de gases generadores del calentamiento global en 5,2\% respecto de los parámetros de 1990.

El Mecanismo de Desarrollo Limpio permite que empresas de países industrializados paguen a otras, en su mayoría empresas de países en vías de desarrollo, por reducir las emisiones de gases del efecto invernadero (GEI), por lo cual se expiden certificados. Estos certificados se conocen como Certificados de Emisiones Reducidas (CERs).

Este sistema basado en incentivos económicos busca contribuir a la mejora de la calidad ambiental y regular la emisión generada por sus procesos productivos, considerando el derecho a emitir dióxido de carbono $\left(\mathrm{CO}_{2}\right)$ como un bien canjeable y con un precio establecido en el mercado. La transacción de los bonos de carbono -un bono de carbono representa el derecho a emitir una tonelada de dióxido de carbono- permite mitigar la generación de gases invernadero, beneficiando a las empresas que no emiten o disminuyen la emisión y haciendo pagar a las que emiten más de lo permitido.

Las reducciones de emisiones de GEI se miden en toneladas de $\mathrm{CO}_{2}$ equivalente, y se traducen en Certificados de Emisiones Reducidas (CERs). Un CER equivale a una tonelada de $\mathrm{CO}_{2}$ que se deja de emitir a la atmósfera, y puede ser vendido en el mercado de carbono. Los tipos de proyecto que pueden aplicar a una certificación son: generación de energía renovable, mejoramiento de eficiencia energética de procesos, forestación, limpieza de lagos y ríos, etc.

Los fondos verdes del Banco Mundial tienen como objetivo generar fondos adicionales para proyectos o programas del Banco Mundial que apoyan las actividades de baja emisión de carbono de sus países clientes, principalmente países en desarrollo. Se supone que el dinero recaudado con la venta de estos bonos se utiliza en proyectos destinados a paliar las causas y consecuencias del cambio climático, a través del desarrollo de instalaciones de energía renovable, iniciativas de reforestación, manejo de aguas residuales y protección contra inundaciones.

\section{Desarrollo sostenible}

Este concepto nace con la Estrategia Mundial para la Conservación de la Naturaleza del Programa de las Naciones Unidas sobre Medio Ambiente, el cual trata de conciliar el desarrollo económico con la conservación

40 El Protocolo de Kyoto es un acuerdo que se enmarca dentro del Convenio Marco de las Naciones Unidas sobre el Cambio Climático (CMNUCC) Fue negociado y acordado en 1997, entró en vigor en el año 2005, tiene como horizonte 2012 y se plantea como un primer paso para conseguir la estabilización de las concentraciones atmosféricas. Establece fundamentalmente límites máximos de emisiones de GEI a los países desarrollados. Estos límites llevan a una reducción global de un $5.2 \%$ entre los años 2012 y 1990. 
y protección de los recursos naturales. En ese sentido, se concibe al desarrollo sustentable como aquel que satisface las necesidades de la presente generación sin comprometer la capacidad de las generaciones futuras para satisfacer sus propios requerimientos.

De esta definición se desprenden tres elementos: la cobertura de necesidades básicas en la presente generación, la capacidad de los sistemas naturales para lograrlo y la cobertura de las necesidades de generaciones futuras.

Jeffrey Sachs, afirma que desarrollo sostenible significa prosperidad compartida globalmente y sostenible desde el punto de vista medioambiental. En la práctica el desarrollo sostenible exigirá tres cambios fundamentales en nuestra tendencia global a seguir:

1. Desarrollar y adoptar a escala global, y en un plazo breve, tecnologías sostenibles.

2. Estabilizar la población mundial, y sobre todo la población de la países más pobres, con el fin de aunar prosperidad económica y sostenibilidad medioambiental,

3. Ayudar a los países más pobres a salir de la trampa de la pobreza.

Estos tres objetivos básicos (sostenibilidad medioambiental, estabilización demográfica y fin de la pobreza extrema) constituyen lógicamente la esencia de las Promesas del Milenio ${ }^{41}$.

El término desarrollo sostenible, sustentable o perdurable se aplica al desarrollo socio-económico y fue formalizado por primera vez en el documento conocido como Informe Brundtland (1987), fruto de los trabajos de la Comisión Mundial de Medio Ambiente y Desarrollo de Naciones Unidas, creada en Asamblea de las Naciones Unidas en 1983.

El desarrollo sustentable consiste pues en el mejoramiento integral del bienestar social de la población y de las actividades económicas de un país, asegurando la conservación permanente de los recursos naturales, la biodiversidad y los servicios ambientales de dicho territorio.

La justificación del desarrollo sostenible proviene tanto del hecho de tener unos recursos naturales limitados (nutrientes en el suelo, agua potable, minerales, etc.), susceptibles de agotarse, como del hecho de que una creciente actividad económica sin más criterio que el económico produce, tanto a escala local como planetaria, graves problemas medioambientales que pueden llegar a ser irreversibles.

De lo que se trata es de concebir un desarrollo que satisfaga las necesidades de la generación actual sin comprometer las de las generaciones futuras, previniendo los posibles impactos ambientales negativos (externalidades negativas) y consiguiendo neutralizar los mismos.

\section{MECANISMOS PARA EVITAR EL CA- LENTAMIENTO GLOBAL}

La actividad humana se organiza en torno a organismos que facilitan la cooperación en el largo plazo. Inicia con la familia y se extiende a organizaciones mayores, el gobierno, la empresa, la comunidad hasta llegar inclusive a organizaciones a nivel mundial como las Naciones Unidas, entre otros.

41 Las Promesas del Milenio son los objetivos del mundo para el desarrollo sostenible y deberían orientar nuestra acción común. Alcanzar estos objetivos requiere un proceso complejo y global, un proceso que excede la capacidad de cualquier gobierno o de cualquier otro sector social en solitario. 


\section{Política ambiental del gobierno}

En general, la intervención pública en materia ambiental, puede llevarse a cabo mediante actividades de $\mathrm{I}+\mathrm{D}+\mathrm{i}^{42}$, controles directos e instrumentos de mercado con la finalidad de resolver los grandes problemas ambientales como el cambio climático, la destrucción de la biodiversidad y el problema de la capa de ozono. Estos problemas son de tal importancia que exigen una actuación rápida y contundente por parte de los gobiernos.

Uno de los mayores retos no superados es el de disponer de un mecanismo de apoyo a la investigación científica en todos los ámbitos, a un determinado nivel y con unas asignaciones acordes con las necesidades globales. Necesitamos formular un compromiso global comparable para financiar actividades de $\mathrm{I}+\mathrm{D}+\mathrm{i}$ para tecnologías sostenibles, entre ellas las energías limpias, las variedades de semillas resistentes a la sequía, la acuicultura sensata desde el punto de vista medioambiental, las vacunas para enfermedades tropicales, la mejora del seguimiento y la conservación a distancia de la biodiversidad.
Hay una necesidad acuciante de financiación pública que incentive las nuevas tecnologías que nos permitan alcanzar al mismo tiempo los objetivos de elevar la renta global, poner fin a la pobreza extrema, estabilizar la población mundial y propiciar la sostenibilidad medioambiental ${ }^{43}$.

Los controles directos constituyen el instrumento más común para la aplicación de políticas ambientales a través de regulaciones convencionales de la actividad económica. Establece normas de obligatorio cumplimiento para los contaminadores. Generalmente, estas normas definen límites de emisiones, de productos intermedios o finales (para garantizar estándares de calidad ambiental), así como procesos técnicos de producción y descontaminación.

Los instrumentos de mercado se definen como aquellos que producen modificaciones en el comportamiento ambiental de los agentes económicos mediante el establecimiento de incentivos económicos, descentralizando las decisiones de emitir a los contaminadores. Los instrumentos económicos más habituales son los impuestos (mecanismos de precio), las subvenciones (mecanismos

42 Las actividades de $\mathrm{I}+\mathrm{D}+\mathrm{i}$ son aquellas actividades relativas a Investigación, Desarrollo Tecnológico e Innovación. La investigación consiste en la indagación original y planificada que persigue descubrir nuevos conocimientos y una superior comprensión en el ámbito científico o tecnológico.

Por tecnología se entiende al conjunto de recursos técnicos propios de una actividad que pueden ser utilizados de forma sistemática para el diseño, desarrollo, fabricación y comercialización de productos o para la prestación de servicios. Finalmente, la innovación es aquella actividad cuyo resultado es la obtención de nuevos productos o procesos, o mejoras sustancialmente significativas, que son incorporadas al proceso productivo y/o mercado.

Se distingue entre: innovación en tecnología, innovación tecnológica, innovación en la gestión e innovación financiera. Se trata de actividades que todos los países tratan de potenciar a través de políticas de investigación (para lo cual se establecen líneas prioritarias de investigación), debido a que un alto nivel de $\mathrm{I}+\mathrm{D}+\mathrm{i}$ implica una mayor fortaleza del país en general y de las empresas en particular, dado que sus productos o procesos se diferencian positivamente de los de su competencia. La mayor parte de las actividades de $\mathrm{I}+\mathrm{D}+\mathrm{i}$ son potencialmente generadoras de mejoras de la calidad de vida (lavadoras, gps, ordenadores), sostenibilidad del medio ambiente (tratamiento de residuos, motores menos contaminantes, procesos industriales ahorradores de energía), la salud (industria farmacéutica, equipos para el tratamiento de enfermedades), etc.

43 Las fundaciones privadas convocan premios que también estimulan el esfuerzo, de los cuales el más famoso es el premio nóbel. La necesidad de financiación pública y filantrópica está ampliamente reconocida en EEUU. Esta es la razón por la que EEUU, destina hasta 100,000 millones de dólares anuales del presupuesto federal a financiar la investigación y el desarrollo. Por desgracia, gran parte de ese dinero se despilfarra en $\mathrm{I}+\mathrm{D}+\mathrm{i}$ militar en sistemas de armamento, lo cual deja muy pocos beneficios, pero el gobierno federal consigue destinar 30,000 millones anuales a la investigación biomédica en los institutos nacionales de salud. 
de precio) y los mercados de derecho de derechos de emisión intercambiables (mecanismos de cantidad). Estos instrumentos introducen flexibilidad en las políticas ambientales al permitir que los agentes reaccionen ante la intervención correctora según sus capacidades, permitiendo que las mejoras ambientales se consigan al mínimo costo para la sociedad.

Jeffrey Sachs afirma que el sector público tiene cuatro responsabilidades principales:

1. Sufragar la investigación científica básica.

2. Promover el desarrollo y la demostración de tecnologías en fases iniciales.

3. Crear un marco político global para la búsqueda de soluciones.

4. Financiar la generalización de innovaciones y tecnologías de éxito.

El proceso arranca con el problema en sí, como la desertización, el cambio climático antropógeno, las tasas de fertilidad excesivamente altas o la pobreza extrema. Los primeros en percibir el problema son los expertos, por regla general los científicos cualificados. Habitualmente, el análisis científico se anticipa en una década o más a la opinión pública. Los científicos sueles formular hipótesis, como los crecientes riesgos del cambio climático, la desaparición de la capa de ozono o la propagación del sida. Cuando las predicciones se confirman, el análisis científico se populariza entre la opinión pública y las esferas de la administración.

Para Sachs, en todos los casos analizados, en relación con el medio ambiente, las enfermedades, la población y la pobreza, hubo acuerdos internacionales muy prematuros $y$ poco incisivos que se sirvieron de la creciente atención científica y la cada vez mayor concientización pública, pero no soluciones acordes a la envergadura del desafío. Los convenios marco de las Naciones Unidas (por ejemplo, sobre la capa de ozono o el cambio climático) son medidas fundamentales, pero no marcan el gran salto a la verdadera acción.

La política ambiental está destinada a preservar la naturaleza de todas las actividades humanas que la afectan. Esto incluye el uso sostenible de los recursos naturales, esto es, desarrollar tecnologías y procedimientos que garanticen la continuidad y calidad de estos, evitando que su utilización los extinga o degrade.

Las áreas naturales protegidas son las reservas naturales que el Perú establece. La Constitución obliga al Estado a promover su conservación.

El desarrollo de la Amazonía es un objetivo importante de nuestro país por la variedad y cantidad de riquezas que engloba. Por lo tanto, la utilización de la Amazonía debe ser sostenible.

Nuestra Constitución establece al respecto lo siguiente:

Artículo 67 "El Estado determina la política nacional del ambiente. Promueve el uso sostenible de sus recursos naturales".

Artículo 68 "El Estado está obligado a promover la conservación de la diversidad biológica y de las áreas naturales protegidas".

Artículo 69 "El Estado promueve el desarrollo sostenible de la Amazonía con una legislación adecuada".

Esta política nacional - entendida como el conjunto de directivas para la acción orgánica del Estado a favor de la defensa y conservación del ambiente - debe permitir el desarrollo integral de todas las generaciones de peruanos que tienen el derecho a gozar de un ambiente adecuado para el bienestar de su existencia.

Todos tienen el deber de conservar dicho ambiente, le corresponde - al Estado - prevenir y controlar la contaminación ambiental.

Los Estados deben propiciar el desarrollo sustentable y establecer las bases para: 
garantizar el derecho de toda persona a vivir en un medio ambiente adecuado para su desarrollo, salud y bienestar; la preservación, la restauración y el mejoramiento del ambiente; la preservación y protección de la biodiversidad; y, la prevención y el control de la contaminación del aire, agua y suelo.

En ese sentido, resulta necesario que los Estados armonicen sus políticas ambientales. La política ambiental debe estar destinada a preservar la naturaleza de todas las actividades humanas que la afectan. Esto incluye el uso sostenible de los recursos naturales, esto es, desarrollar tecnologías y procedimientos que garanticen la continuidad y calidad de estos, evitando que su utilización los extinga o degrade.

\section{Responsabilidad social corporativa}

Según el diccionario de la Real Academia española, el término "Responsabilidad" indica la "obligación de reparar y satisfacer un daño o perjuicio". Otra acepción, que da la Real Academia, es el que se refiere a la responsabilidad como "la deuda u obligación que resulta de un posible yerro."

El impacto que generan nuestras actividades y decisiones en el contexto social nos generan responsabilidades. En ese sentido, la responsabilidad social se refiere al compromiso de reparar un daño producto de los resultados que generen nuestras acciones. Es comprometerse con la sociedad y nuestro entorno; no ser un simple observador de los problemas que atañen al país, sino lograr ser un agente activo de cambio.

Resulta importante comprender que la responsabilidad social comienza donde termina la obligación legal.

El Consejo Empresarial Mundial para el Desarrollo Sostenible (World Business
Council for Sustainable Development, WBCSD), fundado durante el período previo a la Conferencia de la ONU sobre Medio Ambiente y Desarrollo de Río en 1992, utiliza el concepto de responsabilidad social corporativa, definiéndola como el compromiso de las empresas de contribuir al desarrollo económico sostenible, mediante la relación con los empleados y sus familias, la comunidad local y la sociedad en general, con el objetivo de mejorar su calidad de vida.

Cabe precisar, todo titular de operaciones es responsable por las emisiones, efluentes, descargas y demás impactos negativos que se generen sobre el ambiente, la salud y los recursos naturales, como consecuencia de sus actividades. Esta responsabilidad incluye los riesgos y daños ambientales que se generen por acción u omisión.

La responsabilidad social de la empresa es una combinación de aspectos legales, éticos, morales y ambientales, y es una decisión voluntaria, no impuesta, aunque exista cierta normatividad frente al tema. La empresa debe orientar sus esfuerzos no solamente a producir y vender más con el mínimo costo, debe tomar en cuenta el impacto social.

Desde la perspectiva constitucional, y a efectos de su protección, se hace referencia, de modo general, al medio ambiente como el lugar donde el hombre y los seres vivos se desenvuelven. En dicha definición se incluye "tanto el entorno globalmente considerado - espacios naturales y recursos que forman parte de la naturaleza: aire, agua, suelo, flora, fauna - como el entorno urbano"; además, el medio ambiente, así entendido, implica las interrelaciones que entre ellos se producen: clima, paisaje, ecosistema, entre otros ${ }^{44}$.

Por tanto, dentro del contexto de la responsabilidad social, el causante de la degradación del ambiente y de sus componentes,

44 Sentencia del Tribunal Constitucional EXP. N 0048-2004-AI/TC. F.J. 17. Del 01/04/2005. Sentencia citada. 
sea una persona natural o jurídica, pública o privada, está obligado a adoptar inexcusablemente las medidas para su restauración, rehabilitación o reparación según corresponda o, cuando lo anterior no fuera posible, a compensar en términos ambientales los daños generados, sin perjuicio de otras responsabilidades administrativas, civiles o penales a que hubiera lugar.

\section{Ivestigación a través de las Universidades}

Entre las organizaciones que existen, las universidades dedicadas a la investigación, juegan un rol fundamental en el cumplimiento de las promesas del milenio. Sólo las universidades cuentan entre su infraestructura con el vasto espectro de conocimientos científicos especializados que resultan vitales para la resolución de problemas profundos en materia de desarrollo sostenible. Estas organizaciones presentan aspectos fundamentales:

* Tienen perspectiva de largo plazo.

* Pueden ocuparse de problemas globales con menos prejuicios políticos, sociales y económicos que cualquier otra organización.

* En la mayoría de los casos las universidades importantes fueron fundadas con la misión de mejorar el mundo y de hacerlo no sólo arrojando luz sobre problemas mediante la investigación y la educación, sino también marcando una diferencia tanto en las comunidades donde se encuentran como en las demás.

Jorge Basadre en La Vida y la Historia sostiene que "La Universidad es, en principio, una institución educacional, económica, social y nacional. Desde el punto de vista educativo constituye un centro destinado: a) A la conservación, acrecentamiento y transmisión de la cultura;

b) A la formación profesional;

c) A enseñar a los jóvenes a preguntarse por iniciativa propia, cuestiones fundamentales; a buscar libremente la verdad, a pensar con honestidad, a ver las cosas como son y con esa firme base realista proyectarse hacia un futuro mejor $y$ tratar de concretarlo dentro de un mundo que debe cambiar;

d) A tratar que las nuevas generaciones sean conscientes de los valores fundamentales, y también capaces de analizarlos críticamente;

e) $\mathrm{Al}$ fomento de la investigación sin la cual la universidad no es digna de ese nombre."

\section{INSTRUMENTOS DE GESTIÓN AM- BIENTAL}

Los autores Labandeira, León y Vásquez identifican tres instrumentos de gestión ambiental ${ }^{45}$ :

A) Evaluaciones de impacto ambiental (EIA)

La normativa relacionada con la exigencia de estudios y evaluaciones de impacto ambiental a determinadas actividades surgió de forma paralela al establecimiento de límites de emisiones por parte de los gobiernos. Los inicios de estos estudios se encuentran en la National Enviromental Policy Act (NEPA) de los Estados Unidos, aprobada en 1969. Actualmente son una técnica generalizada en todos los países industrializados, recomendada por organismos internacionales como el PNUMA, la OCDE y la UE. En el caso de la UE existe una normativa específica, la

45 LABANDEIRA Xavier - LEÓN Carmelo J. - VÁSQUEZ Xosé, Economía Ambiental, Obra citada, páginas 338-348. 
Directiva 85/377/CE, ampliada en 1997 a un gran número de proyectos. Entre los proyectos que deben realizar evaluación de impacto están las refinerías, las centrales térmicas, las instalaciones químicas, la construcción de autopistas, etc.

El impacto ambiental es el efecto que genera en el medio ambiente cualquier actividad humana y su análisis ha supuesto un avance significativo respecto a la evaluación de la viabilidad de una empresa, actividad, obra pública, etc., añadiendo criterios ambientales a los análisis técnicos y económicos usuales.

Los procesos de Evaluación de Impacto Ambiental son procedimientos jurídicoadministrativos que tienen como objetivo el análisis real y completo (identificación, predicción e interpretación) de los efectos que cualquier actuación tiene sobre el entorno, con el objetivo de prevenir o corregir en la medida de lo posible, estos efectos. Se utiliza normalmente como instrumento de planificación, al servicio de la decisión (el proyecto puede ser aceptado, modificado o rechazado por las Administraciones Públicas a la vista de la EIA ${ }^{46}$.

B) Sistemas de gestión medioambiental (SGMA)

Un SGMA se suele definir como la parte del sistema general de gestión que incluye la estructura organizativa, la planificación de las actividades, las responsabilidades, las prácticas, los procedimientos, procesos y recursos para desarrollar, implantar, llevar a efecto, revisar y actualizar la política medioambiental de la empresa. El objetivo de estos sistemas es promover la mejora en el comportamiento ambiental de las empresas y crear los mecanismos necesarios para que la mejora en materia ambiental sea continua.

El desarrollo de estándares internacionales de Normalización y Certificación $(\mathrm{N}+\mathrm{C})$ relacionados con la actuación de las empresas en materia de medio ambiente han impulsado la aplicación de sistemas de gestión ambiental en las empresas. Normalmente, estos sistemas son de carácter voluntario. El primer Estado, pionero en la publicación de una norma sobre gestión medioambiental, fue el Reino Unido, que en 1992 publicó la norma BS7750. Con posterioridad se desarrolló el Reglamento CEE 1836/93, de Ecogestión y Ecoauditoría (EMAS) en Europa, que tenía como finalidad la unificación de criterios de gestión ambiental que estaban surgiendo en varios países miembros. A la vez el Comité Internacional de Normalización (ISO) ${ }^{47}$, después de regular los temas de calidad en su serio ISO 9000, elaboró las normas de la serie ISO 14000, Sistemas de Gestión Medioambiental, y en el año 1996 fueron publicadas las normas ISO 14001, 14010, 14011 y 14012.

46 Debe diferenciarse el concepto de EIA del Estudio de Impacto Ambiental (EsIA) que son los trabajos encaminados a predecir las consecuencias del proyecto sobre el medio ambiente y establecer medidas correctivas. Es un estudio técnico, interdisciplinar, que normalmente incluye una descripción medioambiental del área afectada antes de la realización del proyecto.

47 Es un organismo no gubernamental, cuyo objetivo primordial es promover el desarrollo de la normalización y actividades relacionadas en el mundo. Además, promueve el desarrollo y la cooperación en la esfera de las actividades intelectuales, científicas y económicas, el resultado de los trabajos de la ISO se refleja finalmente en acuerdos globales, los cuales se publican como normas internacionales.

La labor técnica de creación de las normas se delega en Comités Técnicos, que a su vez pueden integrar varios subcomités, en los que es posible participar, a fin de hacer valer el interés nacional en el ámbito de la Organización. El resultado principal del trabajo del ISO son los acuerdos internacionales que se publican con normas internacionales. Certifica que una empresa emplea procedimientos que le permiten producir bienes con las más altas normas de calidad.. 


\section{C) Auditorías medioambientales o ecoau- ditorías}

Las auditorías medioambientales surgieron en los años setenta en los Estados Unidos como herramienta de la EPA (Enviromental Protection Agency) para evaluar el cumplimiento de la legislación medioambiental, cada vez más compleja y exigente. Actualmente consisten en la evaluación sistemática, documentada, periódica y objetiva de las actividades para detectar su situación en relación con los requerimientos de calidad medioambiental, tanto los derivados de la regulación como aquellos incorporados a las políticas ambientales de la propia empresa.

En las ecoauditorías se utilizan técnicas y procedimientos análogos a los empleados en las evaluaciones de impacto ambiental, aunque de forma más precisa, pues se dispone de datos reales. En general, son un componente fundamental de los SGMA pero no sólo se realizan para conseguir certificaciones sino también para conocer la situación de la empresa frente a la legislación medioambiental y frente a los compromisos voluntarios asumidos tanto externa como internamente.

Las ecoauditorías se pueden clasificar en función de sus objetivos según la siguiente tipología:

a) Auditoría de cumplimiento con la legislación medioambiental. Auditoría básica y consiste en examinar las prácticas y controles de la empresa, en relación con las disposiciones legales vigentes. Suele ser el paso previo a la implantación de un sitema de gestión, porque funciona como un diagnóstico de la situación actual.

b) Auditoría de riesgo medioambiental. Permite evaluar el reisgo medioambiental en que está incurriendo la empresa. Son muy útiles para determinar el valor patrimonial de la empresa a efectos de financiación, compra-venta, seguros, avales, etc. No solo implica evaluar el grado de cumplimiento de la legislación, sino también la capacidad de la empresa para afrontar retos medioambientales a corto y mediano plazo pues la legislación tiende a ser cada vez más restrictiva.

c) Auditoría de declaración medioambiental. Algunas legislaciones como la europea obliga a las empresas a inventariar y declarar los residuos que generan: declarar la cantidad y calidad de sus vertidos y analizar, registrar e informar de sus emisiones. Estas auditorías tienen como objetivo comprobar que los datos de la declaración son compatibles con los que figuran registrados en la empresa, y que su contenido es correcto y completo. Si se realiza a iniciativa de la propia empresa, la información obtenida puede ser utilizada para establecer planes de reducción de emisiones, residuos y vertidos, para así cumplir la legislación y evitar las sanciones administrativas.

d) Auditoría de sistemas de gestión medioambiental. Su objetivo es conocer la eficacia de un sistema de gestión medioambiental implantado y en funcionamiento. Son las auditorías más completas porque incluyen un compromiso de gestión que se prolonga en el tiempo, con la fijación de nuevos objetivos en función de las ya obtenidos.

PROGRAMA NACIONAL DE CONSERVACIÓN DE BOSQUES PARA LA MITIGACIÓN DEL CAMBIO CLIMÁTICO

El 15 de julio de 2010, mediante el Decreto Supremo No 008-2010-MINAM, se creó en nuestro país, el Programa Nacional 
de Conservación de Bosques para la Mitigación del Cambio Climático, el cual está adscrito al Ministerio del Ambiente.

Este Programa de Conservación de Bosques tiene por objetivo central conservar 54 millones de hectáreas de bosque tropicales para mitigar el cambio climático y contribuir al desarrollo sostenible. Asimismo, tiene tres objetivos específicos, que son:

1. Identificar y mapear las áreas para la conservación de bosques.

2. Promover sistemas productivos sostenibles con base en los bosques, que sirvan a su vez, de sustento económico para poblaciones locales más pobres.

3. Fortalecer las capacidades para la conservación de los diferentes actores vinculados al mismo.

El Manual de Operaciones del Programa Nacional de Conservación de Bosques para la Mitigación del Cambio Climático “CONSERVACIÓN DE BOSQUES", citando a la Global Canopy Program 2008, The Little Red Book ${ }^{48}$, sostiene que los bosques tropicales cubren alrededor del $15 \%$ de la superficie del planeta y contienen alrededor del $25 \%$ del carbono en la biosfera terrestre. Sin embargo, están sujetos a procesos de deforestación con lo cual contribuyen con la emisión de dióxido de carbono a la atmósfera. Aproximadamente, 13 millones de hectáreas de bosques se pierden cada año, representando un quinto de las emisiones mundiales de carbono y convirtiendo al cambio de uso del suelo en el segundo mayor contribuyente del calentamiento global. Todo ello demuestra la vital importancia de la conservación de bosques como mitigación al cambio climático.

Asimismo, se afirma que en cuanto al bosque amazónico, del cual el Perú posee el $11.5 \%$ del total, su importancia se refleja en el hecho de que, según el informe del Panel Intergubernamental sobre Cambio Climático (IPCC, por sus siglas en inglés) de 2007, el $65 \%$ del potencial de mitigación de las emisiones de gases de efecto invernadero (GEl) se ubica en los bosques tropicales, siendo que el 50\% de ese potencial se alcanzaría sólo con evitar la deforestación. La Amazonía posee, según el informe 1/Perspectivas del Medio Ambiente en la Amazonía -GEO Amazonía” preparado por la OTCA y el PNUMA (2009), largamente más de la mitad de los bosques tropicales del planeta, de donde se puede deducir que más de la tercera parte del potencial global de reducción de emisiones de GEl está localizado en el bosque amazónico, lo que coloca en primer plano la importancia estratégica de esta región para revertir las tendencias del clima mundial y sus efectos así como para, en el marco de ese proceso, valorizar el bosque amazónico en beneficio de los países que comparten este patrimonio natural.

\section{CONCLUSIONES}

1. El crecimiento desmesurado de la población así como la envergadura de las actividades económicas en el mundo son insostenibles, lo que significa que, si continuamos con nuestras acciones como de costumbre, acabaremos padeciendo una crisis global a nivel social y sobre todo a nivel ecológico de consecuencias catastróficas para las generaciones presentes y futuras.

2. La emisión de gases de efecto invernadero (GEI) es el causante del calentamiento global y por lo tanto, del cambio climático. El $\mathrm{CO}_{2}$ es el GEI más importante. En esa perspectiva, el cambio climático es un

48 Global Canopy Program 2008. The Little Red Book. A guide to governmental and non-governmental proposals for reducing emissions Irom deforestation and degradation. Oxford, 113 pp. 
problema global que implica para su estabilidad acciones conjuntas por los países. En realidad todos comparten cierta responsabilidad, unos más que otros, por el incremento considerable de las emisiones de $\mathrm{CO}_{2}$, ya sean las pasadas o las futuras (que nos han llevado desde las $280 \mathrm{ppm}$ hasta las $380 \mathrm{ppm}$ ). Ninguna parte del mundo podrá librarse de las consecuencias del calentamiento global. Este problema auténticamente mundial exige un plan de acción global en la que cada país asuma verdaderamente un compromiso de responsabilidad social. Precisamente, en el año 1992, los gobiernos del mundo adoptaron el Convenio Marco de las Naciones Unidas sobre el Cambio Climático (CMNUCC). Sin embargo, el problema no es el marco o la finalidad, sino su implantación. El CMNUCC requiere un protocolo para la acción, el primero de los cuales fue el de Kyoto, adoptado en 1997 y vigente hasta el año 2012. Los compromisos de Kyoto fueron muy modestos (una reducción del 5\%) y a corto plazo (hasta el año 2012).

3. La estrategia del desarrollo sostenible implica la necesidad de financiar actividades de $\mathrm{I}+\mathrm{D}+\mathrm{D}$ (investigación, desarrollo y demostración) que incentive nuevas tecnologías sostenibles como energías limpias, las variedades de semillas resistentes a la sequía, la acuicultura sensata desde el punto de vista medioambiental, las vacunas para enfermedades tropicales, la mejora del seguimiento y la conservación a distancia de la biodiversidad, entre otros. Los gobiernos deben alentar, a través de la financiación directa o de incentivos al sector privado, avances importantes en materia de $\mathrm{I}+\mathrm{D}+\mathrm{D}$ de tecnologías energéticas avanzadas y libres de carbono. Según J. Sachs las necesidades de financiación de $\mathrm{I}+\mathrm{D}+\mathrm{D}$ en todo el mundo ascienden probablemente a unos 30,000 millones de dólares anuales como mínimo (cifra comparable a la que destina EEUU a la investigación sanitaria en los Institutos Nacionales de Salud).

4. Un aspecto positivo de todo este incierto futuro sobre el calentamiento global es la aceptación general, al día de hoy, sobre la necesidad urgente de encontrar el equilibrio entre producción-consumo y preservación-conservación.

5. Para gestionar el balance del carbono se requiere: detener la deforestación, econcontrar e implementar mecanismos que permitan la reducción efectiva de emisiones derivadas de la producción de electricidad, minímizar las emisiones lanzadas por los automóviles, sanear unos cuantos procesos industriales de primer orden (acero, cemento, refinerías o las petroquímicas), diseñar viviendas y edificios comerciales de forma que se reduzca en ellos la utilización de combustibles fósiles y se economice en términos generales el consumo de energía, fomentar la eficiencia energética de los edificios, y en el hogar, reducir el consumo de electricidad incrementando la eficiencia de los motores, los aparatos, el aislamiento, y aumentar las superficies vegetales que actúan como sumideros.

\section{REFERENCIAS BIBLIOGRÁFICAS}

1. ANDALUZ WESTREICHER Carlos, Manual de Derecho Ambiental, Editorial Iustitia, 958 páginas, Lima 2009.

2. BRACK EGG Antonio - MENDIOLA VARGAS Cecilia, Ecología del Perú; Segunda Edición, Editorial Bruño, 495 páginas, Lima 2004. 
3. CASTILlO CÓRDOVA Luis. Proceso de Amparo. Código Procesal Constitucional Comentado; Editorial Adrus S.R.L., 1116 páginas, Arequipa 2009.

4. Convenio Marco de las Naciones Unidas sobre el Cambio Climático (CMNUCC).

5. CONSTITUCIÓN POLÍTICA DEL PERÚ 1993.

6. LABANDEIRA Xavier - LEÓN Carmelo J. - VÁSQUEZ Xosé, Economía Ambiental, Editorial Pearson Educación S.A., 356 páginas, España 2007.

7. LEY GENERAL DEL AMBIENTE, Ley No 28611.

8. MINISTERIO DEL AMBIENTE. Manual de Operaciones del Programa Nacional de Conservación de Bosques para la Mitigación del Cambio Climático “CONSERVACIÓN DE BOSQUES".

9. PASCHOAL ROSSETTI José, Introducción a la Economía; Décimo octava edición, Ediciones OXFORD, 866 páginas, México 2000.
10. SACHS Jeffrey, Economía para un planeta abarrotado; Editorial Sudamericana S.A., 527 páginas, Argentina 2008.

11. TRIBUNAL CONSTITUCIONAL. Sentencia del Tribunal Constitucional EXP. No 0048-2004-AI/TC. F.J. 17. Del 01/04/2005. Demanda de inconstitucionalidad interpuesta, en representación de más de cinco mil ciudadanos, contra los artículos $1^{\circ}, 2^{\circ}, 3^{\circ}, 4^{\circ}$ y $5^{\circ}$ de la Ley $\mathrm{N}^{\circ}$ 28258 - Ley de Regalía Minera.

12. TRIBUNAL CONSTITUCIONAL. Sentencia del Tribunal Constitucional. EXP. N ${ }^{\circ}$ 04223-2006-PA/TC. Del 05/09/2007. Demanda de amparo contra la empresa NEXTEL DEL PERÚ S.A. a fin de que se ordene el inmediato desmantelamiento de equipos puesto que su permanencia constituye una grave vulneración al derecho a la paz, a la tranquilidad y a gozar de un ambiente equilibrado y adecuado al desarrollo de la vida, así como el derecho a la salud de los pobladores de dicha urbanización. 